\title{
Street Network Structure \& Crime Risk: An Agent-Based Investigation of the Encounter and Enclosure Hypotheses
}

Daniel Birks, Griffith University (d.birks@griffith.edu.au)

Toby Davies, University College London (toby.davies@ucl.ac.uk)

\begin{abstract}
Street networks shape day-to-day activities in complex ways, dictating where, when, and in what contexts potential victims, offenders and crime preventers interact with one another. Identifying generalizable principles of such influence offers considerable utility to theorists, policy makers, and practitioners. Unfortunately, key difficulties associated with the observation of these interactions, and control of the settings within which they take place, limit traditional empirical approaches that aim to uncover mechanisms linking street network structure with crime risk. Drawing on parallel advances in the formal analyses of street networks and the computational modeling of crime events interactions, this study presents a theoretically informed and empirically validated agent-based model of residential burglary that permits investigation of the relationship between street network structure and crime commission and prevention through guardianship. Using this model, we explore the validity of competing theoretical accounts of street network permeability and crime risk - the encounter (eyes on the street) and enclosure (defensible space) hypotheses. Results of our analyses provide support for both hypotheses, but in doing so, reveal that the relationship between street network permeability and crime is likely non-linear. We discuss the ramifications of these findings for both criminological theory and crime prevention practice.
\end{abstract}




\section{INTRODUCTION}

One of the central principles of environmental criminology is the idea that crime can be understood in terms of the interaction between the key actors involved in criminal events: offenders, victims and preventers (Brantingham \& Brantingham, 1981). From a spatial perspective, one of the most immediate corollaries of this is that the distribution of crime should be influenced by urban morphology: the structure of the built environment determines the places people visit in the course of their day to day activities, the routes they take in moving between them, and the interactions that they experience as they do so. Motivated by this, a substantial volume of research has sought to examine spatial theories of crime by exploring the existence and form of such relationships, with particular emphasis on the role the street network plays in shaping activity. The results of this indicate that not only does the concentration of crime display pronounced regularities at the network level (Weisburd, 2015), but that its variation can be reconciled with the structure of the network (e.g. Davies and Johnson, 2015).

Despite the apparent relationship between network configuration and crime, however, the mechanism by which activity patterns give rise to crime is not well understood. Although environmental theories - most notably Brantingham \& Brantingham's geometric (1981) and pattern (1993a) theories of crime - provide a compelling rationale from the perspective of offender target awareness, the majority of extant empirical evidence is correlational in nature. Furthermore, theoretical perspectives concerned with the influence of other elements in the crime event are much less clear cut. Most notably, the role of guardianship - the third element of the 'crime triangle' - is the subject of several competing discourses (Jacobs, 1961; Newman, 1972), with differing implications for the relationship between movement patterns and crime. This tension is typified by the disparity between the 'encounter' and 'enclosure' principles of urban design.

The encounter and enclosure hypotheses are both concerned with the relationship between movement patterns and crime, but differ in their assessment of the relative contributions of competing mechanisms. Put simply, the encounter hypothesis asserts that the movement of people through places confers a guardianship effect, and that places that experience greater use will therefore be safer. In contrast, the enclosure 
hypothesis suggests that such a guardianship effect is overstated, and in fact is outweighed by the increased exposure to offenders that frequent use implies; it therefore predicts that less readily used - that is, more 'enclosed' - places will be safer. Since the extent to which places are used is determined to a large extent (though not completely) by their position within the wider urban configuration, the street network is of clear relevance in assessing the relative merits of these arguments.

Evidently, therefore, understanding the way in which the street network shapes the interactions that lead to (or, indeed, prevent) crime is of substantial potential significance for theory. Investigating this issue empirically, however, is highly challenging: while correlational studies can reveal associations, the identification of causal mechanisms is hindered by a number of significant obstacles. Some of these are logistical: it is not feasible, for example, to systematically manipulate the structure of real-world street networks to the extent that would be necessary to enable causal inferences in an experimental setting. However, more fundamental difficulties are also a significant barrier to traditional approaches. The inherent difficulty of observing behaviors of interest (e.g. individual movements) means that it typically cannot be established with certainty that a hypothesized mechanism is responsible for an observed spatial pattern (O'Sullivan, 2004). This can be seen most starkly when considering the role of guardianship, which is a phenomenon defined by the absence, rather than presence, of an event: establishing a counterfactual in such cases is highly problematic.

In this paper we aim to gain new insights into the encounter and enclosure hypotheses by combining two recent methodological advances from the field of environmental criminology: a formal approach to network analysis which has recently been applied in empirical studies of crime, and a computational model of offender behavior that has been shown to reproduce many features of real-world offending. Using these techniques, we carry out a series of simulated experiments exploring the relationship between street network structure, individual activity patterns, and several theoretical propositions describing crime commission and guardianship, with the aim of addressing fundamental questions that are largely inaccessible to traditional empirical techniques. In doing so, our primary aim is to examine the theoretical causal sufficiency of the 
encounter and enclosure hypotheses by investigating the extent to, and means by, which guardianship effects, as shaped by the street network, influence the volume and distribution of property crime, in this case - mirroring much of the extant empirical research - focusing on residential burglary. In building towards this, we also explore the relationship between network structure and offending more generally, seeking insight into the behavioral mechanisms which offer a causally explicit account of crime concentration at the street segment level.

The remainder of the paper is structured as follows. We begin by describing extant theoretical and empirical research that considers the relationship between street network structure and crime risk. We then outline the computational agent-based modeling approach we leverage to increase this understanding. Subsequently, we describe our scientific instrument: an agent-based model of residential burglary and its explicit theoretical underpinnings. We integrate these sections as a means of specifying both the model itself and the decisions made in its construction. Having described our instrument, we present several tests of its validity before proceeding to set out a series of simulation experiments that utilize it to address our primary research question. Subsequently, we present our findings and discuss their ramifications for both the theories that underlie our model and crime prevention interventions that draw upon them. We conclude by discussing several potential weaknesses of our approach, and by setting out how - in continuing our research in this area - we aim to address them.

\section{THEORETICAL BACKGROUND}

Much of the theory concerned with the relationship between environment and crime is grounded in the basic framework provided by routine activity theory (Cohen and Felson, 1979). This sets out the fundamental observation that, in order for a direct-contact crime to occur, three elements must coincide in time and space: a suitable target, a motivated offender, and the absence of a capable guardian. From this assertion it follows that the overall spatio-temporal characteristics of crime can be understood in terms of the movements and behaviors of these three elements. 
As the primary substrate for routine human activities, the street network plays a crucial role in determining where the convergences of these elements occur. In many cases, potential targets are located, and thus encountered by offenders, at some position on the network: this is particularly apparent for crimes against fixed targets, such as burglary, but also applies to interpersonal crimes that take place in the urban environment. In addition, offenders will typically use the street network when travelling to and from offences. Importantly, these principles apply not only to the movements and presence of offenders, but to those of citizens in general, thereby influencing the supply of potential guardians at particular places. In all these cases, the locations and movements of the key actors involved in the crime event are largely constrained by the structure of the street network.

The idea that the street network is a crucial structure in understanding the role of environment in crime is at the heart of crime pattern theory (Brantingham and Brantingham, 1993a; Brantingham, Brantingham \& Andresen, 2017). Pattern theory asserts that offenders typically choose to offend against targets they encounter during non-criminal activities. This is conceptualized as a process by which offenders build up 'awareness spaces' of familiarity in the course of their daily lives; according to the theory, it is where these spaces intersect with attractive criminal opportunities that offenders are most likely to commit crime. Framed in this way, understanding the distribution of crime is equivalent to understanding where targets are most likely to be encountered by potential offenders. Where the population of potential offenders is large, this involves understanding which places are likely to feature most prominently in the aggregated awareness spaces of the population as a whole.

Since awareness spaces are built up in the course of routine activities, their shape and extent are governed by the movement patterns that are generated during these activities. In pattern theory, it is suggested that these activity spaces are structured around a small number of key 'activity nodes' (e.g. homes, workplaces or entertainment facilities) which act as anchors for movement (Golledge and Spector, 1978). It is around these nodes, and on the routes between them, that awareness is thought to be centered, and it is in places where they overlap for many people that elevated levels of crime may be observed. 
Since travel plays such a key role in the formation of awareness spaces, it is natural to expect that the street network should exert an influence. In particular, the reasoning of pattern theory can be refined to reflect this: rather than thinking of awareness spaces as amorphous forms, they can be more concretely specified in terms of the routes and streets that they comprise. Framed in these terms, it is along popular or easily accessible streets that the greatest exposure to potential victimization is to be anticipated (if all else is equal). Since these characteristics are determined to some extent by the position of streets within their wider network, this invites analysis of the relationship between the structural properties of streets and their criminal character.

Although the range of structural properties that can be considered for networks is large, a small number are particularly pertinent to the arguments outlined above. The concepts of 'permeability' and 'connectivity' are frequently invoked in discussions of crime and urban form (Johnson \& Bowers, 2010; Brantingham \& Brantingham, 1993b) and, while neither are typically defined in formal terms, both refer to the ease and regularity with which places can be accessed. Such concepts can be considered at the global or local level: street networks are permeable if they are readily accessible or encourage through movement (White, 1990), and individual streets are highly connected if they carry relatively high volumes of traffic (Davies \& Johnson, 2015). From both perspectives, the basic hypothesis is the same: greater connectivity implies greater exposure, both to cities as a whole and to particular locations within them.

\section{ENCOUNTER AND ENCLOSURE}

While the argument that highly-connected streets will be subject to greater offender awareness is a compelling one, the question of whether this will be manifested in higher levels of crime is, however, far from straightforward. This is because the reasoning presented so far concerns only two of the elements for crime - the target and the offender - while failing to account for the effect of guardianship. The implications in this regard are much less clear, and a tension exists between two alternative views, known commonly as the 'encounter' and 'enclosure' hypotheses. 
The encounter hypothesis is based on the observation that a large proportion of potential guardians (i.e. the public at large) will be subject to the same movement principles as offenders: that is, they will tend to flow along more 'central' streets (in the sense of their role in movement patterns). Thus, the supply of potential guardians will be greatest in such places, and they will be more likely to be present when opportunities for crime arise. If this provides a sufficient deterrent effect, it is argued, then more connected streets ought to be safer: Jacobs' (1961) notion of natural surveillance through 'eyes on the street' captures this idea succinctly. If this is the case, then networks that encourage through flow - and therefore encounters - are least susceptible to crime.

The enclosure hypothesis provides an alternative perspective to this, arguing that the deterrent effect on which the encounter hypothesis relies is overstated. The rationale for this concerns the largely transient nature of traffic on highly-connected streets: passers-by may be inattentive, and their presence may even provide cover to outsiders. If the level of deterrence is not sufficient to counteract the increased exposure in such places, then they will experience higher risk. According to this argument, crime will be prevented when places are 'enclosed': reducing through traffic of potential offenders, limiting their awareness of viable criminal opportunities, and promoting locals' abilities to recognize and respond to outsiders and potential wrong-doers, in line with the notion of 'defensible space' proposed by Newman (1972).

The encounter and enclosure arguments have diverging implications for the expected distribution of crime across street networks. As such, they represent testable hypotheses: empirical examination of patterns at the network level can provide support or otherwise for each argument (and thus offer insight into the nature of guardianship in urban areas). This can be done by comparing observed patterns of crime against measures of network structure that reflect the behavioral principles outlined above. 


\section{STREET NETWORK STRUCTURE AND CRIME RISK}

A number of empirical studies have examined the relationship between network structure and crime risk.

The majority of these have concerned themselves with residential burglary, which is analytically convenient and constitutes a natural application of crime pattern theory. The studies do vary considerably, however, in their measurement of network properties, with each capturing a subtly different aspect of network structure.

The earliest example of network analysis within criminology is the study of Bevis and Nutter (1977), which examined residential burglary in Minneapolis, USA. At the local level, it was found that more connected block types (through streets, as opposed to cul-de-sacs, for example) experienced greater levels of crime. In addition, the study also included area-level analysis, in which the street network density in each census tract (defined as the ratio of segments to junctions) was measured. This metric - which corresponds to a general notion of permeability - was found to be positively associated with burglary risk.

White (1990) also studied residential burglary at the area level, instead examining neighborhoods in Massachusetts, USA, from the perspective of accessibility. In particular, the number of direct connections to a major road was measured for each area, with this providing an indication of accessibility to external traffic. Again, this was found to be positively associated with risk, suggesting that these connections had the effect of exposing those areas to offenders. Several more recent studies have focused on the street segment as a primary unit of analysis. Beavon, Brantingham and Brantingham (1994), for example, used the number of neighboring streets as a measure of each segment's connectivity in Ridge Meadows, Canada. This was again found to be positively associated with burglary risk, after controlling for other demographic factors.

Crime has also been studied using an approach known as 'space syntax', which seeks to quantify urban form by building networks based on lines of sight (see Hillier, 1996). Findings from London and Australia conflict somewhat with earlier research, with less connected streets found to be safer (Hillier, 2004). Notably, however, this relationship was found to be reversed when additional permeability was added in the form of alleys and other potential escape routes. The work of Johnson and Bowers (2010) also examined 
street segments, with their number of immediate neighbors and administrative classification used as measures of connectivity. Using a nested statistical approach, they also found that higher connectivity was associated with greater burglary risk.

A particular challenge when studying the street network concerns how to measure the structure of networks in a way that reflects their use. Many of the measures typically employed suffer from a number of shortcomings: either they offer little granularity (as with street classification) or relate obliquely to true patterns of use (e.g. number of connections). Davies and Johnson (2015) sought to address this by applying terminology and techniques from the mathematical field of graph theory. Their study considered the network measure 'betweenness', which estimates how frequently street segments will be used in travel through the network. This was shown to be positively associated with burglary risk in Birmingham, UK, suggesting that exposure to movement flows is indeed associated with victimization. In addition, a variant of betweenness has also been shown to predict offender target choice at the street segment level (Frith, Johnson and Fry, 2017).

It is clear from the literature that, for the crime of residential burglary at least, street connectivity is positively associated with crime risk. Nevertheless, a number of questions remain unanswered.

Significantly, the correlational nature of previous studies dictates that the underlying behavioral hypotheses have not been rigorously tested; possible confounding factors which vary systematically across street types cannot yet be ruled out (Davies and Johnson, 2015). Furthermore, the contribution of guardianship is not known: these patterns may arise because of, or in spite of, variation in the presence of guardians. In order to investigate the existence and form of a causal relationship between centrality and crime, it is necessary to examine how variations in network structure influence the distribution of crime while controlling for all other potential sources of variation.

Ideally, issues of causality such as this are investigated using an experimental approach, in which the hypothesized cause is manipulated and the effect observed. In the present context, however, this is clearly 
not feasible, since it is not possible to systematically manipulate the structure of real-world street networks. This fact alone precludes traditional experimentation, and indicates that a new approach is required. Drawing on recent advances in the study of individual level crime event mechanisms, in this study, we employ a computational modelling approach which allows us to explore the implications of behavioral theories in a synthetic environment that confers absolute observation and manipulation (Townsley and Birks, 2008). In doing so, our goal is to construct a computational laboratory, which encodes individuallevel behavioral theory, and through which the impact of varying street configurations on crime and guardianship events can be systematically explored, free from logistical constraints that have constrained empirical investigation in this significant area of enquiry. Doing so allows us to examine the theoretical causal sufficiency of the theories encoded in the model, with the hope of guiding subsequent theoretical advancement and, where appropriate, complementary empirical efforts.

\section{COMPUTATIONAL CRIMINOLOGY AND AGENT-BASED MODELLING}

Recently, a number of studies have demonstrated how agent-based models (ABM) can provide insight into the complex systems that produce crime events and the theoretical models we use to describe them (e.g. Birks, Townsley and Stewart, 2012; Groff 2007, Weisburd et al, 2017). ABM allow researchers to create artificial societies and populate them with simulated actors - referred to as agents - whose characteristics and behaviors are derived from theoretical propositions and/or empirical insight. Analyzing the interactions of these synthetic populations, and the aggregate outcomes that emerge as a result, ABM explore the causal links between proposed individual behavior and aggregate societal outcomes (Epstein and Axtell, 1996). This is a task that is largely inaccessible to empirical approaches, due to host of constraints associated with observing, manipulating and characterizing human systems (Birks, Townsley and Stewart, 2014; Bonabeau, 2002).

Constructing models that formalize key propositions of criminological theory, ABM provide the means to assess theoretical causal sufficiency: the degree to which a proposed construct is capable of generating outcome patterns compatible with reality (Birks, Townsley and Stewart, 2012). Where competing accounts 
exist, $\mathrm{ABM}$ can thus be used to conduct a form of "theoretical" experimentation, where system components are systematically manipulated to reflect differing configurations of assumptions, and the causal sufficiency of each is assessed. In this way, ABM enable in-silico social science, where confidence in theoretical accounts can be strengthened or weakened through simulation (Epstein, 1999).

To illustrate, Birks, Townsley and Stewart (2012) describe an ABM of residential burglary in which an abstract urban environment is inhabited by offender agents whose movement, target selection and learning behaviors are derived from key propositions of routine activity theory, rational choice perspective and crime pattern theory. Performing a series of controlled experiments, the authors demonstrate that patterns of simulated crime exhibit both individual and aggregate level offending patterns that are congruent with a range of empirical signatures of residential burglary, in turn strengthening confidence in the validity of theories enacted within the model.

Where a plausible model of crime events is constructed - that is, one that produces a range of outcome regularities consistent with those observed in empirical study (Berk, 2008) - ABM can also be used to explore the potential impacts of changes to actor behaviors or environmental configurations that might ultimately be manipulated in real world settings. In this way, ABM offer a platform to prototype potential crime prevention intervention prior to costly empirical study (Birks, 2017; Groff and Birks, 2008; Weisburd et al., 2017).

Here, for those unfamiliar with the approach, it is important to note that while ABM are capable of ascertaining theoretical sufficiency, they cannot identify the necessity of a proposed explanation. Neither can they replace empirical study: their outputs represent only the logical consequences of the assumptions upon which they are grounded. Nevertheless, when triangulated with theoretical and empirical efforts, ABM support a new and insightful approach to hypothesis testing and theory building. It is under this rationale that we now proceed and indeed that are results should subsequently be interpreted. 


\section{RESEARCH AIM}

In this paper, we seek to address two key research questions concerning the relationship between urban morphology and crime risk:

- How does street network structure influence the distribution of crime risk?

- To what extent are the encounter and enclosure hypotheses supported by the spatial variation in guardianship effects?

The first of these questions acts as a foundation for the latter: by determining how and where street morphologies influence the interactions that lead to crime occur, we establish a baseline against which we can quantify the viability of guardianship effects proposed by theory.

To investigate these issues, we build on ABM published in Birks, Townsley and Stewart $(2012,2014)$ and employ a model of residential burglary in a stylized urban environment that is both theoretically and empirically informed. Following previous research, we validate this model by assessing its ability to generate multiple distinct patterns of crime consistently observed in empirical studies of residential burglary. Having done so, we examine our primary research questions by carrying out a series of controlled simulation experiments that systematically manipulate the simulated street network structure in ways that would be infeasible through traditional empirical enquiry.

By carrying out our analysis in a generalized framework - rather than attempting to replicate any particular setting - we aim to shed light on the fundamental relationships proposed by competing theoretical accounts that link street network structure, activity patterns, crime risk and guardianship. Consequently, it is important to note that while a range of factors undoubtedly influence burglary risk - such as investment in security, home occupancy, etc. - here, we seek only to provide insight into the underlying dynamics that link network permeability and crime risk as put forward by the encounter and enclosure hypotheses. Indeed, it is this accumulation of potentially explanatory factors that obfuscate our understanding via empirical study, and thus motivates application of the model, which, in turn, enables a separation of such factors wholly 
untenable in traditional research. To this end, we now describe the primary scientific instrument associated with our study - a computational ABM of residential burglary.

\section{METHOD}

\section{THEORETICAL AND COMPUTATIONAL MODEL}

We conceive an abstract urban environment inhabited by three types of agent: offenders, citizens, and residential properties. We simulate residential burglary events that take place when motivated offender agents going about routine activities find known, attractive targets in the absence of capable guardians. We use this model to examine how systematic manipulations to the street network shape patterns of crime event actor activity and convergence, and, in turn, the impacts these have on both the volume and distribution of property victimization. In addition, following assertions of the encounter and enclosure hypotheses, we investigate the role that passer-by guardianship plays in shaping these relationships, considering - in the absence of compelling empirical evidence - several theoretically-informed hypotheses concerning its extent and deterrent effect ${ }^{1}$.

The model operationalizes the following underlying assumptions:

1. Offenders and non-offenders undertake routinized, spatially structured activities (via the street network) that primarily originate from their home (Brantingham and Brantingham, 1981; Golledge and Spector, 1978).

2. Offenders find targets for crime going about these day-to-day activities (Brantingham and Brantingham, 1981).

3. Offenders consider some targets more attractive than others (Cornish and Clarke, 1986).

4. Offenders incrementally develop awareness of the locations they frequent, such that increased awareness aids in the commission of crime at these locations (Brantingham and Brantingham, 1981).

\footnotetext{
${ }^{1}$ Our model is implemented using Netlogo, "a multi-agent programmable modeling environment" (Wilensky, 1999) that has been widely used in both the natural and social sciences.
} 
5. In order for a crime to occur a motivated offender must converge with a suitable target in the absence of capable guardians (Cohen and Felson, 1979).

6. Guardians who prevent crime are typically people going about their day-to-day activities (Felson and Eckert, 2015; Reynald, 2011).

7. The capability of potential guardians to prevent crime is variable and context dependent (Reynald, 2011).

The model is now described in more detail. In addition, Appendix A also summarizes its key parameters, the constructs they seek to capture, and their associated initialization and manipulation conditions.

\section{MODEL ENVIRONMENT}

In our model, agents act and interact on an abstract urban street network. It is via this street network that all activities take place, in turn dictating where and when offenders find potential targets, and where and when guardians are present to potentially protect them from victimization. The environment is made up of three key components: street links, intersections, and property nodes. This environmental model and its construction are now described.

○

๑

○
○

๑

$\odot$

(A)

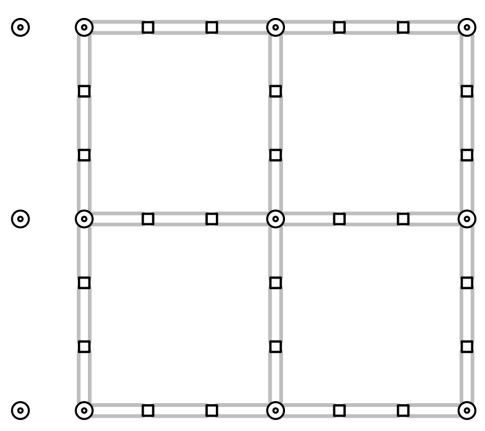

(B)

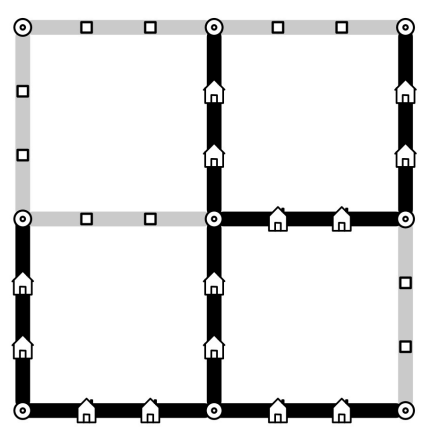

(C)

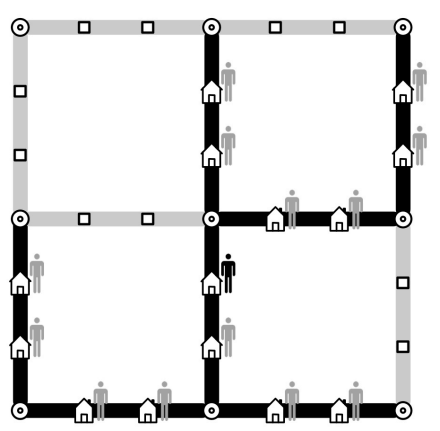

(D)

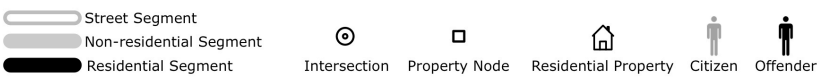

Figure 1. Stepwise simulation environment initialization. Panels show: (A) placement of intersections; (B) arrangement of property nodes and street links between them; (C) selection of residential segments; and (D) assignment of citizens and offenders to residences. 
1. The simulated street network conforms to a standard block-based layout, and its instantiation begins with the creation of a uniform grid of intersections (see Figure 1a).

2. Between each pair of intersections, a uniform number of property nodes - representing land parcels - are created. The connections between neighboring property nodes and intersections are referred to as street links (which collectively between two intersections constitute a 'street segment' in the traditional sense). Figure $1 \mathrm{~b}$ depicts an illustrative environment of $3 \times 3$ intersections, with two property nodes (and therefore 3 street links) per segment. In our simulations, we use a grid of $15 \times 15$ intersections with 10 property nodes per segment.

3. $50 \%$ of all streets segments are designated as residential streets, leaving the remaining $50 \%$ as nonresidential (see Figure 1c).

4. For each residential street, a residential property agent is instantiated at each property node (see Figure 1c), and a measure of its target utility is randomly generated (see below).

5. For each residential property agent, an occupant agent is instantiated (see Figure 1d). This occupant can be a citizen agent (with $p=.95$ ) or an offender agent (with $p=.05)^{2}$.

6. Depending upon the experimental configuration of the model, any manipulations to the street network are performed (see below)

Having described the simulation environment, we now specify the agents that act within it.

\section{AGENTS}

Our model incorporates three classes of agent: residential properties, citizens and offenders. We now describe these agents, their characteristics, behaviors and the theoretical and/or empirical rationale that underlies their inclusion in the model.

\footnotetext{
${ }^{2}$ In addition to this offender-citizen ratio, we also explore the impact of increasing and decreasing the proportion of offenders in a series of robustness tests presented in Table 6.
} 


\section{RESIDENTIAL PROPERTY AGENTS}

Residential burglary involves commission of crime at a residential property. Thus, potential targets for our simulated offenders are represented as residential property agents. Each residential property agent stores a single characteristic representing its attractiveness to offenders: utility. Drawing from the rational choice perspective's depiction of criminal decision making (and previous computational formalizations of it - see Birks, Townsley and Stewart 2012, 2014), this measure encapsulates the rewards, risks and efforts associated with victimizing a target. It can be considered as the outcome of a cost/benefit calculus, such that utility increases as rewards become greater and risks/efforts decrease (and vice versa). In terms of model behavior, utility simply represents the probability that an offender agent will find a target attractive, and is incorporated into offender agents' offending behavior (see below). Utility is heterogeneous across residential property agents and generated uniformly at random in the range $[0,1]$.

\section{OFFENDER AND CITIZEN AGENTS}

Two further types of agent inhabit the simulated environment: offenders and citizens (non-offenders). Their characteristics and behaviors are now summarized.

\section{CHARACTERISTICS:}

Home Location: All citizen and offender agents are allocated a home location in the form of a residential property agent. It is here that an agent is instantiated when the model is initialized.

Routine Activity Space: In addition to the home node, both offender and citizen agents are allocated a routine activity space that consists of four ${ }^{3}$ other randomly selected property nodes. These may or may not host a residential property agent, and therefore represent both residential (e.g. homes of friends or family) and non-residential (e.g. workplace, bar) routine activity nodes).

\section{BEHAVIORS:}

\footnotetext{
${ }^{3}$ The selection of four activity nodes mirrors the approach taken in Birks, Townsley and Stewart (2012, 2014), where additional robustness testing demonstrated minimal impact from differing numbers of routine activity nodes (see Birks, Townsley and Stewart, 2012, p242).
} 
In our model, offender agents employ three key behaviors - navigation, learning and offending - and citizen agents employ two - navigation and guardianship. These behaviors, and their theoretical and empirical underpinnings, are now described.

\section{NAVIGATION BEHAVIOUR (CITIZEN AND OFFENDER AGENTS)}

Drawing on crime pattern theory, routine activity theory, and more general assertions of human geography, both offender and citizen agents undertake anchor-based (Golledge and Spector, 1978) routinized spatial activities. Following Birks, Townsley and Stewart (2012, 2014), agents begin the simulation at their home location, from where they randomly select one of their routine activity nodes at random and travel to it via the street network. Once a routine activity node is reached, agents either return to their home location (with high probability, $p=.8$ ) or randomly select another routine activity node and navigate to it (with $p=.2$ ).

Navigation is performed using a simple shortest path algorithm (Dijkstra, 1959): agents plan a route to their destination ${ }^{4}$, and follow it in discrete jumps between property nodes and intersections (traversing one street link at each step).

\section{LEARNING BEHAVIOR (OFFENDER AGENTS)}

Crime pattern theory proposes that as individuals go about their day-to-day activities they develop awareness spaces that reflect knowledge of their local environment. Since offenders tend to commit crime at locations known to them, it is argued, these spaces determine where an individual's offending is most likely to occur. Following Birks, Townsley and Stewart $(2012,2014)$, we conceptualize a learning behavior that allows offender agents to build up awareness of the locations they visit. When a simulation is initialized, offender agents have no awareness of their environment; subsequently, the relationship between time spent at a location and an offender's awareness of it follows a simple logistic function:

$$
\operatorname{awareness}_{(\mathrm{s})}=\left(\frac{1}{1+\mathrm{e}^{-\left(\frac{\mathrm{t}(\mathrm{s})}{\mathrm{b}}\right)}}\right)
$$

\footnotetext{
${ }^{4}$ In the event that there are multiple paths of equal length between origin and destination, one is selected at random.
} 
Where $t(s)$ is the time spent at location $s, b$ the rate at which offender agents learn about the locations they visit $^{5}$, and $e$ denotes the exponential function. Using this behavior, offender agents incrementally build awareness spaces that reflect knowledge of their local environment; in principle, this awareness value simply represents the probability that an agent is sufficiently aware of a location to consider committing crime there.

\section{OFFENDING BEHAVIOUR (OFFENDER AGENTS)}

We conceptualize an offending behavior that incorporates key propositions of the routine activity approach, rational choice perspective and crime pattern theory. Whenever an offender agent encounters a residential property node during its routine movements, it decides whether to attempt commission against that target. This decision is made probabilistically, on the basis of a behavioral calculus which takes into account: (1) the offender's motivation ${ }^{6}$; (2) the utility of the target (see above); and (3) the offender's awareness of the target location. This is calculated as the product of these quantities, so that the probability of commission at a location $s$ and time $t$ is given by:

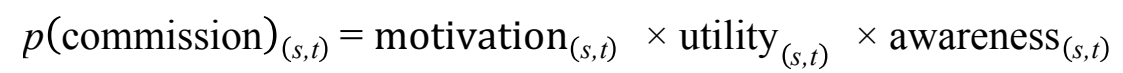

The decision taken here refers to the intention to commit crime; that is, it determines that crime will take place in the absence of all other effects. However, our model also incorporates guardianship effects, whereby the presence of one or more citizen agents at the commission of crime may dissuade an offender and therefore prevent victimization from occurring.

\section{MODELLING GUARDIANSHIP}

\footnotetext{
${ }^{5}$ As in Birks, Townsley and Stewart $(2012,2014)$ the learning rate is selected such that offender awareness of a given location approaches 1 after it has been visited 50 times.

${ }^{6}$ As in Birks, Townsley and Stewart $(2012,2014)$ given our focus on proximal influences of crime rather than criminality, offender motivation was considered uniform across all model configurations $(p=.1)$.
} 
Modeling guardianship poses a particular challenge in an agent-based context, since there is little empirical evidence on which to base the specification of behaviors (see Hollis-Peel et al, 2011). Though guardianship itself is well researched, few studies address the issue being considered here - that is, guardianship in the course of routine interactions - in a quantitative way. Not only does this limit grounding for the model, but it also poses problems for validation: the lack of stylized empirical facts (guardianship is, by nature, largely unobserved) means there is little basis to assess validity.

We attempt to address these challenges in three main ways. First, the model we employ is a minimal one, in the sense that it a) is restricted to only the form of guardianship that is relevant to our research question, and b) includes only those basic features that would be common to any such model. While this means that our model does not provide a comprehensive account of guardianship, it minimizes the number of assumptions we must make. Second, in recognition that these assumptions while both theoretically and empirically informed, are undesirable, we also explore the robustness and sensitivity of our findings under variations to this mechanism. Third, in the absence of established empirical regularities concerning guardianship itself, we assess the validity of the model by examining the consistency of its outputs with both consistent patterns of residential burglary (as in Birks, Townsley and Stewart, 2012), and those of correlational studies examining the relationship between network structure and crime risk. Asserting that while guardianship was not the explicit focus of these, its effect must necessarily be present and therefore accounted for in observed results.

Our model of guardianship is grounded in the routine activity approach, so that the presence of a citizen agent at the point where an offender agent encounters a residential property may prevent the commission of crime. Given the focus of this study, we consider only 'on street' guardianship; that is, that provided by passers-by during routine activities, and consequently influenced by variations in street morphology. While it is certainly true that other forms of guardianship will play a role in the real world - most notably home occupancy (see Garofalo \& Clark, 1992) - they are not directly relevant to the key issues of encounter and enclosure: there is no reason to expect that such effects will vary with urban configuration. In addition, we 
assume that guardianship occurs only at the point of commission. While this is a simplification, it mirrors approaches taken in previous ABM that incorporate guardianship (e.g. Bosse, Elffers and Gerritsen, 2010; Groff, 2007). Furthermore, any more complex formulation would require further assumptions, and would be likely to simply amplify the effects already present.

Since their implications for the model are identical, we also make no distinction here between active guardianship, whereby an individual intervenes during commission, or passive guardianship, whereby the presence of that individual deters an offender (unbeknownst to the guardian; see Felson \& Eckert, 2015). The extent to which these effects disrupt crime is unknown; however, evidence suggests that capability depends on several contextual factors (Reynald, 2011). In particular, there is empirical support for the role of territoriality (Brown \& Altman, 1981; Reynald \& Elffers, 2009), in line with Newman's (1972) theory of Defensible Space, and we thus incorporate a simple mechanism that increases or decreases citizen's guardianship capability dependent on context.

\section{GUARDIANSHIP BEHAVIOR (CITIZEN AGENTS)}

Following the rationale described above, the underlying guardianship mechanism is identical in all model configurations, and is enacted whenever one or more citizen agents are present when an offender decides to attempt victimization of a residential property agent. In such cases, each citizen has a probability $p(g u a r d)$ of providing capable guardianship and thus preventing commission. Importantly, each potential guardian acts independently: if more than one is present then each in turn may prevent the crime (and it will only occur if none do; conversely, if one is successful in preventing crime no other citizen may also prevent that crime). If, under this calculus, a citizen does prevent an offender from successfully offending we describe this as a guardianship event. In exploring this behavior, we manipulate both the presence of guardians and their capability based on context.

Guardianship Configuration A (Control): In the first model configuration, the world is inhabited only by offenders, who (for the sake of establishing an appropriate comparator) we assume cannot provide 
guardianship ${ }^{7}$. This control configuration allows us to observe the impact of street network manipulations on the occurrence of crime in the absence of any guardianship effect. This provides a baseline measure of the influence of the street network on target-offender convergences, and the effect of guardianship can be measured by comparison with this.

Guardianship Configuration B (Defensible Space): In our second model configuration, we populate the environment with citizen agents who have the potential to act as guardians when present at an attempted crime commission. In keeping with Newman's defensible space hypothesis, these citizens have a greater propensity to prevent crimes occurring on their home street than those that they encounter elsewhere. In particular, when a citizen agent is present at the attempted commission of crime on their home street segment, there is a one in three chance they will prevent crime; that is, $p(\text { guard })_{\text {home }}=.33$. Conversely, if they encounter crime away from home, their capability is reduced to the extent that they have only a one in five chance (i.e. $\left.p(\text { guard })_{\text {away }}=.20\right)$. Although these values are consistent with those found in experiments concerned with the willingness to intervene in property crime (e.g. Moriarty, 1975; Hindelang, Gottfredson \& Garofalo, 1978), we acknowledge that they remain relatively arbitrary. We also therefore explore the robustness of our primary results with respect to two further conceptualizations of capability.

In the first, Guardianship Configuration C (Uniform Capability), we set $p$ (guard) $=.2$ in all circumstances, so that citizen agents have a one in five chance of preventing crimes they encounter, regardless of whether they are on their home street. In the second, Guardianship Configuration D (Strong Home Advantage), we explore a stronger version of our defensible space conceptualization, in which the capability of preventing crime on the home street is increased to one in two - i.e. $p(\text { guard })_{h o m e}=.50$-while capability away from home remains $p(\text { guard })_{a w a y}=.20$. We undertake these ancillary experiments to ensure that the results of our primary experiments are not wholly driven by the capability assumption, for which we have the least empirical support. Results of these experiments are discussed in the robustness section of our results section.

\footnotetext{
${ }^{7}$ While unlikely a reflection of reality, we prevent offenders from acting as guardians. This is done to allow the control model (where only offender agents are modelled) to represent the complete absence of guardianship, and subsequently to allow direct comparisons between this and other model configurations.
} 


\section{THE SIMULATION CYCLE}

As with all ABM, our model simulates the repeated actions and interactions of agents at discrete time intervals called cycles. At each simulated cycle, all agents execute a series of behaviors that represent a single sequence of perception, cognition and action. The order in which these occur is as follows: (1) citizen and offender agents execute movement behavior; (2) where appropriate, offender agents execute offending behaviors, and, where relevant, citizen agents execute guardianship behavior; (3) offender agents execute learning behavior.

\section{SIMULATION EXPERIMENTS}

Our primary interest in this study concerns the role of the street network in shaping the interactions between offenders, targets and guardians, and the consequences of this for the level and distribution of crime. In order to examine this, we manipulate the structure of our simulated street network in ways which affect the movements and interactions of agents, and observe the resulting patterns of both crime and guardianship events. Since all other factors are held constant throughout these manipulations, this allows us to isolate the effect of urban form, and assess the relative merits of the encounter and enclosure hypotheses.

The manipulations we carry out are designed to gradually reduce the permeability of the simulated street network. This is accomplished by randomly removing the connections between some terminal property nodes (i.e. those at the end/start of a street) and their neighboring intersections; in effect, converting through-streets to cul-de-sacs. This procedure maintains the configuration of property nodes in the street network while altering the structure of viable paths that exist within it. This causes changes in the relative usage of street segments, whereby some segments may experience substantial increases in use, for example, as agent navigation paths are re-routed to take account of the new structure.

Figure 2 depicts illustrative manipulations of a simple model environment and the resultant impact on a single agent's navigation between their home node and, in this example, activity node 2. Plot 2 A represents 
our control model configuration - a fully connected grid - and subsequent plots 2B-2E depict the shortest paths used by the same offender agent as a result of incremental street closures.

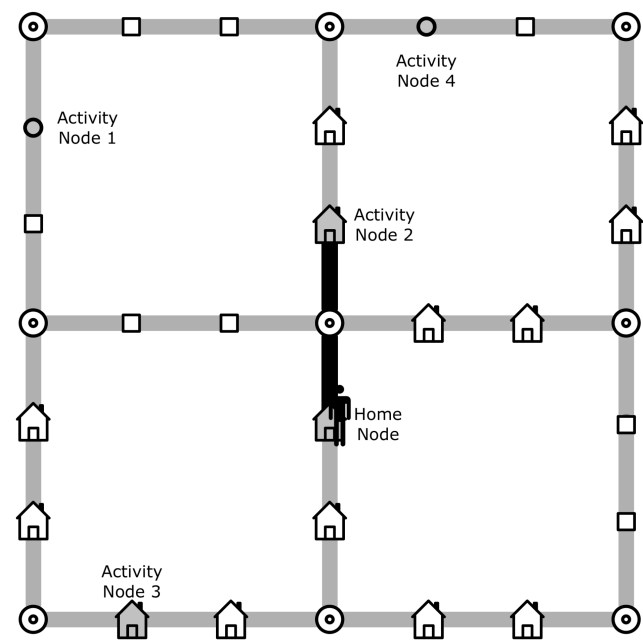

(A) Control Model

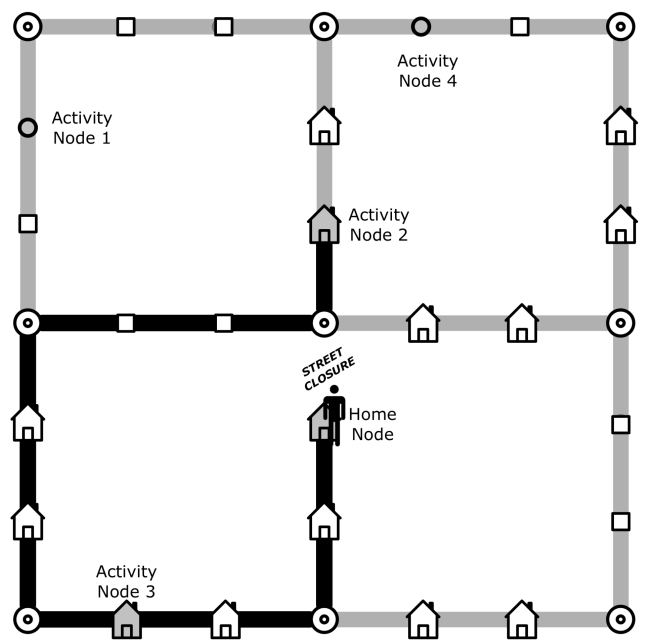

(B) 1 Street Closed

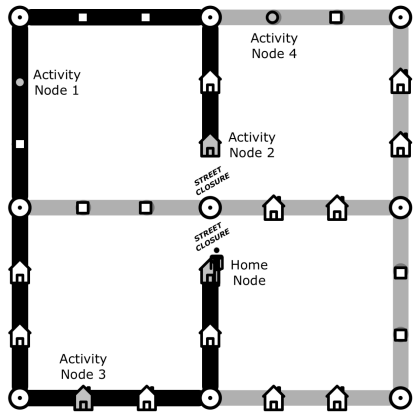

(C) 2 Streets Closed

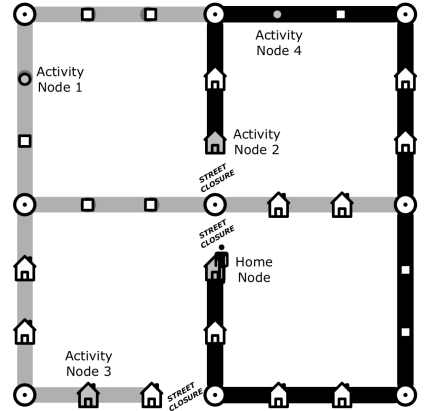

(D) 3 Streets Closed

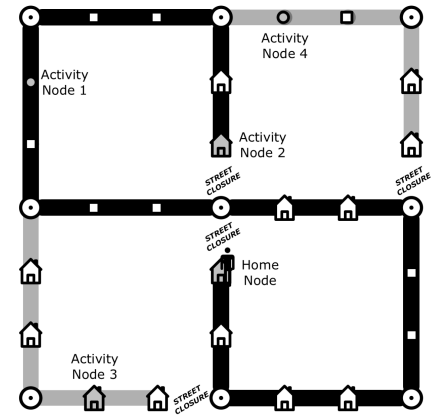

(E) 4 Streets Closed

Figure 2. Impact of network manipulation on agent navigation. Panels show how the shortest route between an offender's home and selected activity node changes as links are removed.

\section{EXPERIMENTAL SCHEDULE}

We perform simulations under five distinct environmental configurations: a fully connected street network (our control model) and four increasingly disconnected networks. To generate these, we begin by initializing a fully-connected network - including environmental characteristics - and then proceed to gradually 
disconnect segments using the procedure described above. At each stage, we disconnect $10 \%$ of segments ${ }^{8}$, so that we eventually have networks with $10 \%, 20 \%, 30 \%$ and $40 \%$ of the original streets disconnected ${ }^{9}$.

The fact that these environments are derived sequentially (i.e. the closure of streets is cumulative) is crucial, since it means that, aside from network structure, all other components of the experimental environments remain unchanged across the five conditions. Thus, residential property nodes and their ascribed utility characteristics, and the routine activity spaces of offenders and citizen agents, remain fixed across each of the 5 environmental configurations, and only the configuration of the street network upon which agents navigate alters. Figure 3 depicts 5 such environmental configurations.

Each simulation is run for 25,000 cycles, and, since our model is stochastic, it is necessary to repeat each simulation multiple times. We therefore replicate our simulations of the five environmental configurations 100 times, with a different randomly-generated initial configuration each time ${ }^{10}$. Because the environmental conditions are held constant over the five conditions in each case, our approach is equivalent to systematically closing street segments through five increasingly disconnected configurations in 100 distinct study areas.

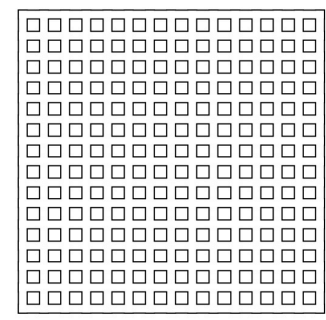

$0 \%$ streets closed

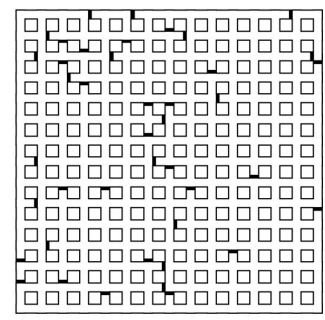

$10 \%$ streets closed

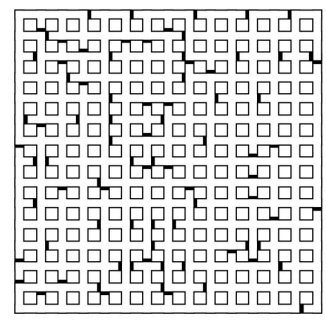

$20 \%$ streets closed

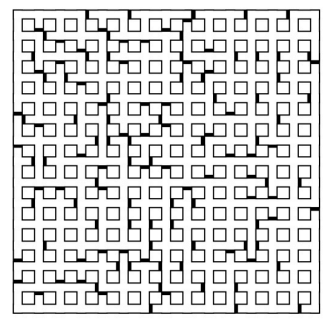

$30 \%$ streets closed

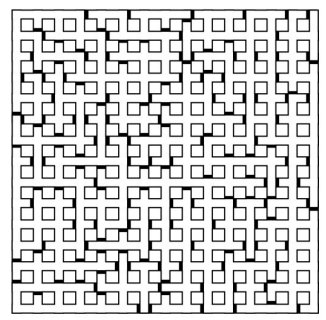

$40 \%$ streets closed

Figure 3. Cumulative street network manipulation (seed $=100)$. At each stage, a proportion of street segments are randomly selected for disconnection, resulting in an increasingly irregular

\footnotetext{
${ }^{8}$ In selecting street links for closure we ensure that the street network remains connected; that is, that all locations remain accessible from all others.

${ }^{9}$ Note that such closures do not reflect any proposed intervention strategy, but simply offer a parsimonious means to manipulate network connectivity without fundamentally changing the layout of the network or the number of property nodes within it.

${ }^{10}$ Following observations of Lee at al (2015), selection of the total number of cycles a model is run for, and the number of replications per configuration, were informed by preliminary analyses of variance stability - that is, by examining the variance of key outcome variances.
} 
structure.

In addition to these environmental manipulations, we also vary the guardianship behavior, exploring the two conceptualizations discussed above and the two further robustness configurations. Thus, our experiments can be cast in a traditional 5 (environmental configurations) x 4 (guardianship configurations) design, producing 20 unique experimental configurations, for each of which 100 replications are carried out.

\section{FINDINGS}

Before carrying out our experiments we must first validate the base model of offending (Berk, 2008, Birks and Elffers 2014; Groff and Birks, 2008). We do this by assessing whether simulated crime patterns are compatible with consistently-observed empirical patterns of residential burglary. For reasons of brevity, we do not describe these tests here - they are explained in detail in Birks, Townsley and Stewart (2012) - and the results are shown in Appendix B. In summary, we observe simulated burglary patterns that mimic those observed empirically, such that they are (1) spatially concentrated; (2) disproportionally experienced by a small number of repeat victims; and (3) display a distance decay relationship in the journey-to-crime.

This finding is in fact a meaningful extension of the tests of theory presented by Birks et al (2012) because our new model incorporates a theoretically informed guardianship mechanism that was absent in the earlier model. In light of the incorporation of this new behavior we see that simulated crime patterns still remain consistent with those observed empirically.

Having demonstrated that our model produces plausible outcomes we now detail the results of our experiments that seek to estimate the impact of street network permeability on offending and guardianship. We divide these into three distinct analytical studies, the first addressing the impact of global street network permeability on offending levels, and the second and third considering the influence of permeability at the individual street segment level. At both spatial levels, results in the guardianship-free configuration offer insight into the role of the network in shaping offender-target interactions. Having established this baseline, 
the addition of guardianship allows us to quantify its effect, which in turn informs our assessment of the encounter and enclosure hypotheses.

\section{STUDY 1: MACRO-SCALE IMPACTS: THE RELATIONSHIP BETWEEN GLOBAL STREET NETWORK PERMEABILITY AND CRIME RISK.}

Table 1 below depicts the relationship between global network permeability and incidence of both crime and guardianship events. The first of these refers to a successful crime commission against a residential property agent by an offender agent, while the latter represents the successful prevention of a crime event by an onstreet citizen agent enacting the guardianship behavior. These results are summarized across both our control and defensible space configurations of guardianship.

Several primary observations can be made from examination of Table 1. First, in both realizations of the guardianship behavior there is a curve-linear relationship between network permeability and crime commission. This relationship sees moderate reductions in network permeability $(\approx 10-20 \%$ road closures $)$ resulting in increased levels of victimization. Subsequently, at some inflection point $(\approx 30 \%$ road closures $)$ further reductions in permeability lead to overall reductions in the incidence of crime.

Table 1. Mean and Standard Deviation of Crime and Guardianship Event Counts by Network Permeability and Guardianship Configuration (100 model replications).

\begin{tabular}{|c|c|c|c|c|}
\hline \multicolumn{3}{|c|}{ Crime Events } & \multicolumn{2}{|c|}{ Guardianship Events } \\
\hline 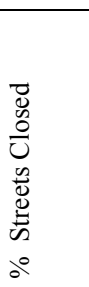 & $\begin{array}{l}\text { Guardianship } \\
\text { configuration A: } \\
\text { control (no } \\
\text { guardians) }\end{array}$ & $\begin{array}{l}\text { Guardianship } \\
\text { configuration B: } \\
\text { defensible space }\end{array}$ & $\begin{array}{l}\text { Guardianship } \\
\text { configuration A: } \\
\text { control (no } \\
\text { guardians) }\end{array}$ & $\begin{array}{l}\text { Guardianship } \\
\text { configuration B: } \\
\text { defensible space }\end{array}$ \\
\hline $0 \%$ & $719(127)$ & $611(98)$ & $0(0)$ & $73(16)$ \\
\hline $10 \%$ & $757(125)$ & $642(114)$ & $0(0)$ & $90(22)$ \\
\hline $20 \%$ & $770(126)$ & $655(112)$ & $0(0)$ & $107(27)$ \\
\hline $30 \%$ & $714(113)$ & $583(106)$ & $0(0)$ & $129(30)$ \\
\hline $40 \%$ & $544(103)$ & $394(94)$ & $0(0)$ & $145(37)$ \\
\hline
\end{tabular}


The results for configuration A represent an important benchmark, since they show how the model behaves in the absence of guardianship. The pattern observed in these cases cannot be due to guardianship events, and must therefore be caused exclusively by changes in offender behavior. The nature of these can be reasoned by considering the evolution of offender awareness spaces.

When the network is completely regular, offenders have a plurality of routes for each possible journey, and their awareness is therefore relatively diffuse. The removal of connections has the effect of concentrating their activity on particular routes, thereby increasing their awareness and probability of offending, and ultimately leading to the initial increase in victimization. Further network manipulation, however, has the effect of lengthening paths as agents are forced to take more convoluted routes: Figure 4 shows how the lengths of offenders' routine trips vary across the 5 environmental configurations. This lengthening of trips means that offenders take fewer trips, on average, over the course of a simulation: while their movements are concentrated on certain (longer) routes, they visit the locations on those routes less frequently. This has the effect of diluting awareness, and the fact that agents no longer have a high level of familiarity with a small number of targets leads to an overall reduction in risk.

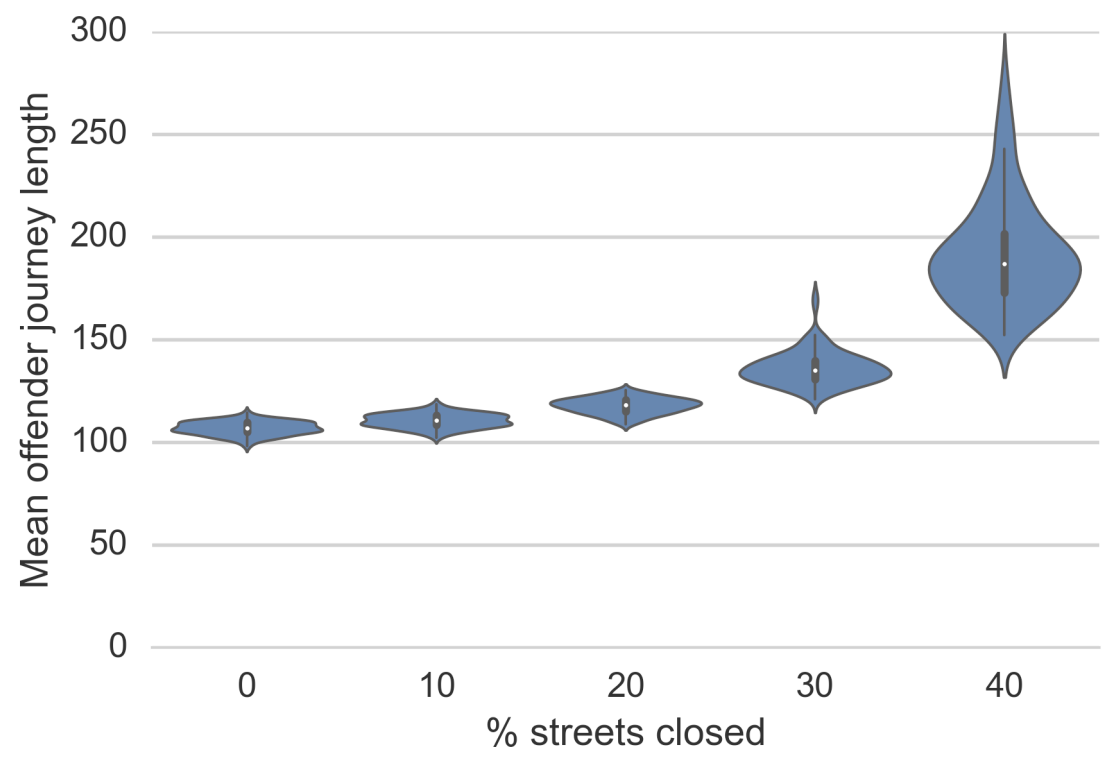

Figure 4. Violin Plots depicting the distribution of trip lengths for offender journeys between home locations and routine activity nodes by Network Permeability Configuration. Values presented are averaged across all replications. 
Further consideration of the above point suggests an alternative approach to the comparison of results across configurations. The fact that the average number of trips completed by agents varies across simulations means that, while model runs are equivalent with respect to opportunities encountered by offenders (in that offenders evaluate the same number of potential targets in all configurations), they may not be in terms of the volume of routine activity they represent. Since trips, rather than model cycles, may be considered the basic unit of routine activity, it is necessary to adjust the results in order to compare simulation runs over equivalent volumes of activity (i.e. numbers of trips). To do this, we rescale the results for each simulation by dividing by the average number of trips completed by offenders in each case: this gives a measure of the number of crime and guardianship events 'per trip'. Results of these analyses are shown in Table 2 and Figure 5.

Table 2. Mean and Standard Deviation of Crime and Guardianship Rates, Rescaled by Trip Count (100 model replications).

\begin{tabular}{|c|c|c|c|c|}
\hline & Crime Rate & & Guardianship Rat & \\
\hline 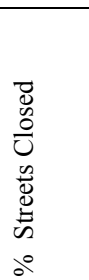 & $\begin{array}{l}\text { Guardianship } \\
\text { configuration A: } \\
\text { control (no } \\
\text { guardians) }\end{array}$ & $\begin{array}{l}\text { Guardianship } \\
\text { configuration B: } \\
\text { defensible space }\end{array}$ & $\begin{array}{l}\text { Guardianship } \\
\text { configuration A: } \\
\text { control (no } \\
\text { guardians) }\end{array}$ & $\begin{array}{l}\text { Guardianship } \\
\text { configuration B: } \\
\text { defensible space }\end{array}$ \\
\hline $0 \%$ & $3.07(0.56)$ & $2.61(0.40)$ & $0(0)$ & $0.31(0.07)$ \\
\hline $10 \%$ & $3.35(0.57)$ & $2.83(0.49)$ & $0(0)$ & $0.40(0.10)$ \\
\hline $20 \%$ & $3.63(0.62)$ & $3.08(0.50)$ & $0(0)$ & $0.50(0.12)$ \\
\hline $30 \%$ & $3.88(0.64)$ & $3.16(0.52)$ & $0(0)$ & $0.70(0.18)$ \\
\hline $40 \%$ & $4.17(0.94)$ & $2.95(0.48)$ & $0(0)$ & $1.10(0.26)$ \\
\hline
\end{tabular}




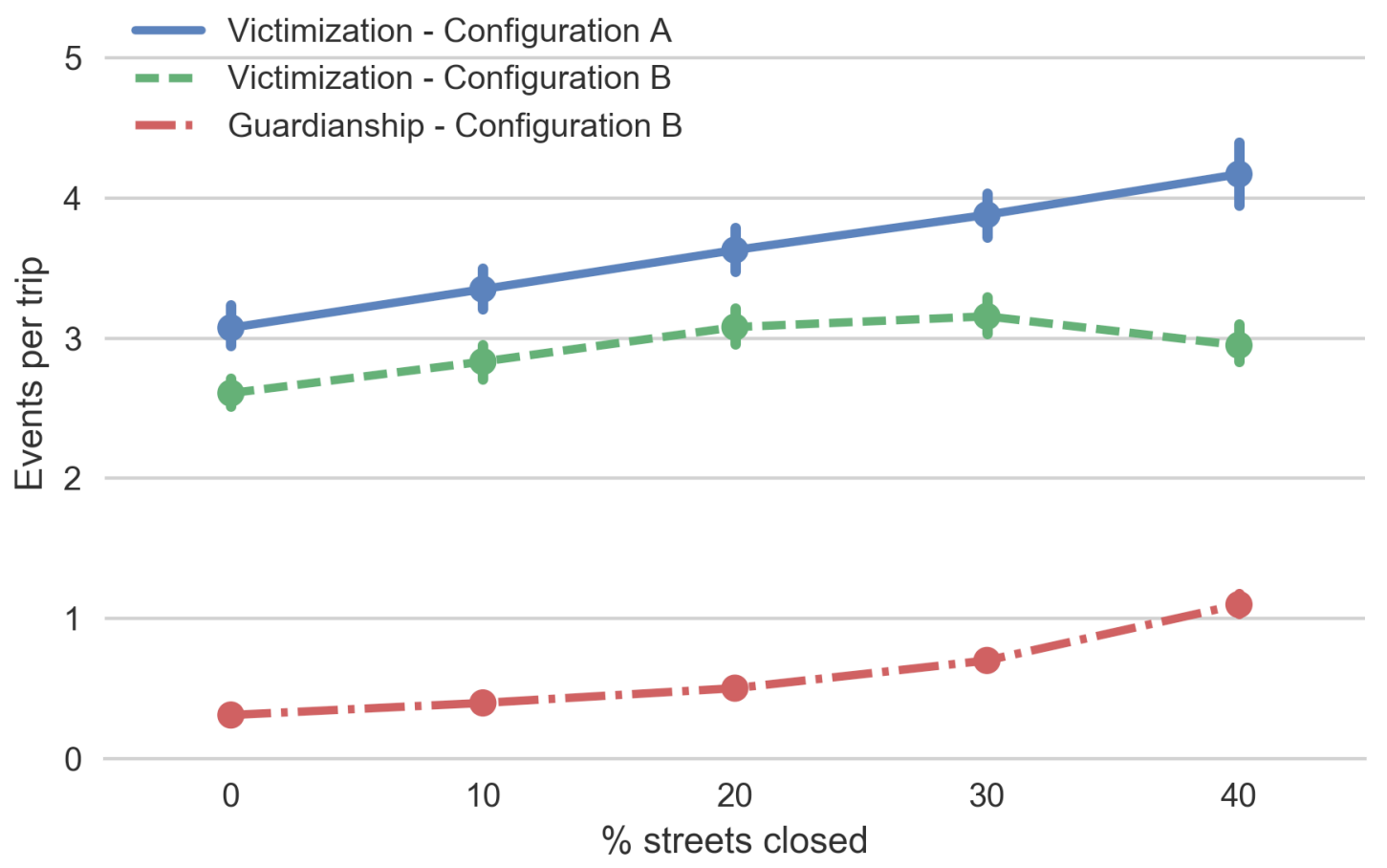

Figure 5. Variation in the mean volume of victimization and guardianship events across environmental configurations. The values plotted represent the volume of events 'per trip'; that is, raw counts have been rescaled by dividing by the mean number of routine trips carried out by offenders in each simulation.

Under this rescaling, there is a qualitative change in the relationship with permeability for configuration A: the decrease in victimization for more irregular networks is no longer present, with the adjusted victimization rates instead continuing to rise. To a large extent, this can be explained by the fact that offenders in these environments travel further on each trip, and so encounter more targets: all else being equal, they will therefore commit more crimes per trip. Nevertheless, comparison of Figures 4 and 5 shows that this factor is not in itself sufficient to explain the trend in victimization: if it were, the per-trip victimization rate would be directly proportional to the average trip length in each case. The fact that the increase in victimization rate is approximately linear, and lags behind the super-linear increase in trip lengths, implies that there remains a reduction in per-encounter risk for more irregular networks.

The results for configuration B are qualitatively similar in both raw and rescaled versions: an initial increase in victimization as networks become less permeable, followed by a decrease at higher levels of irregularity. This pattern can be reconciled with the trend in guardianship events, the numbers of which increase super- 
linearly as permeability is reduced. The turning point occurs when the increase in guardianship is sufficient to counteract the increase in offending that was identified in configuration $\mathrm{A}$, leading to an overall decrease in victimization.

In overall terms, this finding supports the enclosure hypothesis, in the sense that decreases in network permeability ultimately lead to reductions in crime. However, it should be noted that the mechanism by which this takes place is yet to be established, and may, in fact, be consistent with elements of the encounter hypothesis. In particular, one possibility is that the increases in guardianship we observe result from the increased concentration of both offenders and guardians on routes that become increasingly central as a result of cumulative reductions in network permeability. If this is the case, increases in offender-targetguardian convergences on these routes may result in a localized 'eyes on the street' guardianship effect, driving macro-level reductions in crime. If so, this raises the possibility that the encounter hypothesis may be true in a local sense - that is, on individual streets - while the enclosure hypothesis is reflected in the aggregated results. Indeed, the enclosure hypothesis may be supported, in part, because it concentrates and accentuates encounter-like effects on certain parts of the network. In order to investigate whether this is the case, it is necessary to examine the distribution of both crime and guardianship events across the individual streets which form the network.

\section{STUDY 2. MICRO-LEVEL IMPACTS: THE RELATIONSHIP BETWEEN LOCAL STREET SEGMENT BETWEENNESS AND CRIME RISK.}

Having investigated the behavior of our model at the aggregate level, we now consider the patterns that it generates in spatial terms. In particular, we explore one of the central themes of the paper: the way in which the distribution of criminal activity is shaped by the structure of the street network. On one hand, this is done with the aim of further validating the model, by examining the extent to which the patterns it generates are consistent with real-world empirical studies. However, our experimental setup allows us to go further than this, by exploring how the influence of the network varies under changes in its structure. 
As outlined previously, our primary interest concerns the relationship between street centrality, offender targeting and guardianship. Following assertions of the encounter and enclosure hypotheses, we wish to explore the role of the network in shaping the interactions between offenders, targets and citizens, and to establish whether increases in such interactions in our model are associated with either greater risk (due to exposure) or greater security (due to guardianship). To begin, we examine the hypothesis that street segments which are more likely to feature in the activity spaces of individuals will experience higher levels of victimization. This was the issue investigated by Davies and Johnson (2015) and, in order to assess the consistency of model outputs with their empirical findings, we take a similar approach to theirs.

In Davies and Johnson's work, it was argued that the likely prominence of individual streets in activity spaces could be quantified using the network metric 'betweenness'. Betweenness measures the number of times that a street features in paths through the network, thereby providing a proxy measure for the level of traffic it is likely to experience. It can be defined formally using graph-theoretic notation (see Davies \& Johnson, 2015), but the principle can be illustrated most clearly by describing how it is calculated:

- Initialize a betweenness value of 0 for all segments

- Consider all pairs of vertices, $v$ and $w$

- In each case, find the shortest path(s) through the network between $v$ and $w$

- For each segment that appears on one of these paths, increment its betweenness by $1 / m$, where $m$ is the number of shortest paths between $v$ and $w$ ( $m$ will only be greater than 1 when multiple distinct paths have exactly the same length)

For any network, therefore, betweenness is a measure of the extent to which movement activity is concentrated on particular segments. As such, its overall distribution is highly dependent on network structure: the greater the extent to which traffic is 'funneled' down particular streets (and therefore away from others), the more dispersed the values of betweenness will be. In real-world settings, variation in these structural characteristics cannot be explored independently of other factors, since network structures are fixed. Our systematic variation of network structure, however, allows us to do this: Figure 6 shows how 
betweenness is affected by cumulative street closures, in terms of its spatial patterning (top row) and numerical distribution (bottom row) ${ }^{11}$.

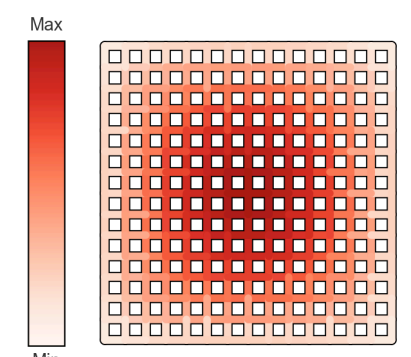

$0 \%$ streets closed

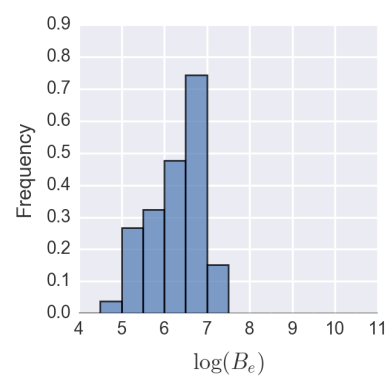

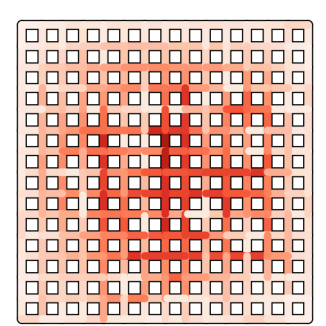

$10 \%$ streets closed

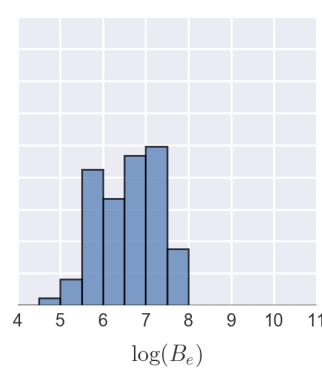

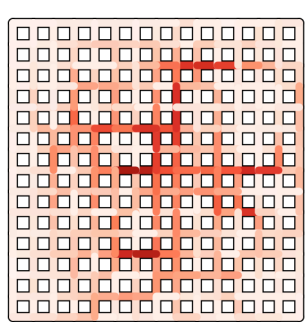

$20 \%$ streets closed

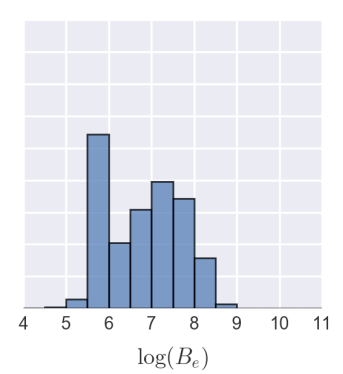

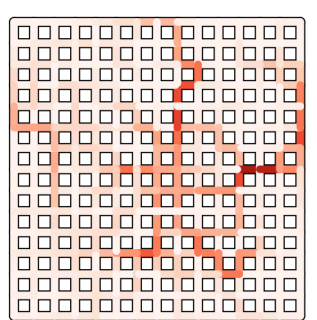

$30 \%$ streets closed

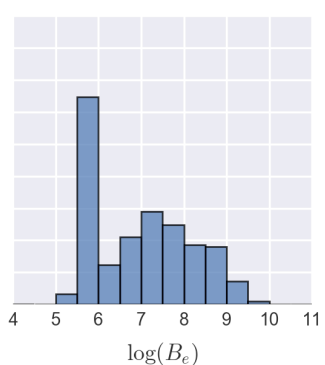

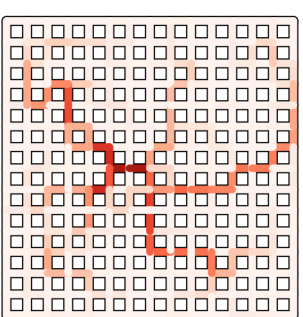

$40 \%$ streets closed

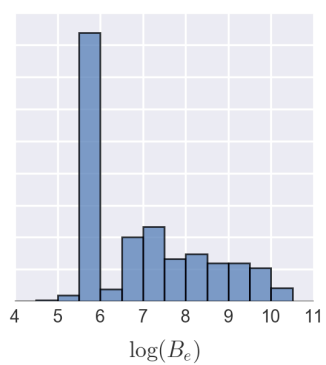

Figure 6. Cumulative street network manipulation and corresponding betweenness (seed = 100). Top row reflects spatial patterning of betweenness. Bottom row histograms of the logarithm of betweenness across all segments in the environment.

From an analytical perspective, our setting is relatively simple: whereas real-world studies must control for variation in factors such as opportunity (e.g. address count) and property characteristics (e.g. investment in security), all residential streets in our environment are known to be identical in all respects other than their position in the network. Quantifying the influence of network structure is therefore simply a matter of examining the bivariate relationship between crime risk and betweenness. Since the distribution of betweenness is approximately exponential, we first take its logarithm (as is done by Davies and Johnson).

Since our data is spatial in nature, it is also necessary to employ an analytical method which accounts for the possibility that spatial autocorrelation is present. Preliminary diagnostic analysis shows that the data is indeed spatially autocorrelated, and in order to adjust for this we employ a 'spatial error' regression model (Anselin, 1988). This is a regression model which incorporates spatial dependence between error terms and

\footnotetext{
${ }^{11}$ Though betweenness is subject to edge effects, their inclusion is not unrealistic since they reflect lower usage patterns at the outskirts of urban areas.
} 
corrects for spatial structure. For our models, this results in an increase in log-likelihood relative to ordinary least-squares regression.

In Table 3, we present regression coefficients for the effect of betweenness on the proportion (i.e. normalized count) of victimization across all street segments ${ }^{12}$. In each case, average values across all 100 model environments are given, along with their standard deviations. The most immediate observation that can be made here is that a positive relationship between crime risk and betweenness is apparent in all cases. This result agrees with the findings of Davies \& Johnson (and, indeed, with crime pattern theory) and suggests that the model produces behaviors that are consistent with reality in this sense.

Table 3. Spatial Regression Coefficients - Street Segment Betweenness vs. Proportion of Crime Events*.

\begin{tabular}{|c|c|c|}
\hline \multirow{3}{*}{ 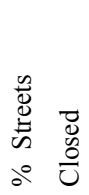 } & Guardianship & Guardianship \\
\hline & Configuration A: & Configuration B: \\
\hline & Control - No Guardians & Defensible Space \\
\hline $0 \%$ & $4.35(1.09)$ & $3.82(1.26)$ \\
\hline $10 \%$ & $4.50(1.13)$ & $3.73(1.17)$ \\
\hline $20 \%$ & $4.88(0.94)$ & $4.30(1.03)$ \\
\hline $30 \%$ & $5.71(0.82)$ & $4.93(0.85)$ \\
\hline $40 \%$ & $7.18(0.97)$ & $6.10(0.78)$ \\
\hline
\end{tabular}

\footnotetext{
* For each replication $(n=100)$, regression is performed on the 210 residential street segments in each environment; the mean of these values is given in this table, and the figures in brackets give the standard deviations.
}

A second notable observation is that the association between victimization and betweenness becomes stronger as the networks become more irregular. This can be rationalized by considering that one of the effects of street closure is to increase the variance between streets in terms of their activity levels (as illustrated in Figure 6). From the perspective of offender-target interaction, this implies that crime will be more concentrated on certain streets - those which are more central - and betweenness therefore represents

\footnotetext{
${ }^{12}$ Note that, because values are normalized against the total volume of events in each simulation, the issue of variable trip length identified for Study 1 is not a factor here. The analysis relates only to the distribution of offending across the network, regardless of its total volume.
} 
a more powerful predictor of offending levels. Essentially, the increased variation in betweenness means that it carries more information with respect to exposure to offenders.

Our results also show how the relationship with betweenness is affected by the introduction of guardianship. The coefficients for configuration B, while still positive, are lower than those for configuration A at all levels. The reason for this is the increased guardianship effect on higher-betweenness streets as a result of their greater supply of potential guardians. This means that some events which would otherwise have resulted in victimization are instead prevented, therefore moderating the effect of betweenness in exposing those targets to offenders.

This effect can in fact be tested by examining the proportion of crime events that are prevented on each segment. Specifically, we can define the prevention rate, $r_{p}$ as

$$
r_{p}=\frac{\# \text { guardianship events }}{\# \text { guardianship events }+\# \text { crime events }}
$$

The denominator of this expression is the total number of potential crime events (all of which would result in victimization, in the absence of guardianship), and $r_{p}$ therefore represents the probability that an event will be prevented by guardianship. To examine this, we adopt the same spatial regression approach used for victimization, and in Table 4 we show regression coefficients for the relationship between $r_{p}$ and betweenness for configuration $\mathrm{B}$. 


\begin{tabular}{|c|c|}
\hline \multirow{3}{*}{ 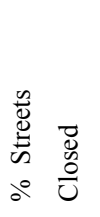 } & Guardianship \\
\hline & Configuration B: \\
\hline & Defensible Space \\
\hline $0 \%$ & $6.32(1.44)$ \\
\hline $10 \%$ & $7.17(1.16)$ \\
\hline $20 \%$ & $7.23(1.01)$ \\
\hline $30 \%$ & $7.67(1.01)$ \\
\hline $40 \%$ & $8.61(0.92)$ \\
\hline
\end{tabular}

\footnotetext{
* For each replication $(\mathrm{n}=100)$, regression is performed on the 210 residential street segments in each environment; the mean of these values is given in this table, and the figures in brackets give the standard deviations.
}

It is evident here that prevention rate is positively associated with betweenness, and that - as with victimization itself - the relationship is stronger for more irregular networks. Put simply, this means that crimes are more likely to be prevented on more central streets, as would be expected given their greater supply of potential guardians.

Taken together, these results allow us to reflect on the overall effect of network structure on crime risk. It is clear that guardianship is more strongly manifested on more central streets, in the sense that individual offences are more likely to be prevented. However, the fact that victimization is also higher on these segments implies that this effect is not sufficient to counteract the increased exposure to potential offenders. In other words, the risk to more central streets is sufficiently great that, even if a higher proportion of offences are prevented, they are still likely to experience more victimization.

In terms of the encounter and enclosure hypotheses, these results have several implications. The fact that less accessible locations experience lower crime - in both the presence and absence of guardianship - is clearly in accordance with the enclosure hypothesis, and implies that the intersection of offender awareness and viable criminal opportunities provide the dominant driver of crime. On the other hand, the high risk associated with high-betweenness streets, even when guardianship is introduced, appears to cast doubt on the encounter hypothesis. However, consideration of this in tandem with the findings of Study 1 again 
demonstrates the distinction between local and global effects. The fact that increasing the irregularity of networks ultimately leads to reductions in crime at the macro level means that the overall effect is positive: the reduction in risk on low-betweenness streets outweighs the increase on more central streets. As the regression results show, this is because of the greater rate of guardianship on those streets: crimes are pushed towards more central streets, where they are more readily prevented.

\section{STUDY 3: MICRO-LEVEL IMPACTS: THE RELATIONSHIP BETWEEN SUCCESSIVE STREET}

\section{SEGMENT MANIPULATION AND CRIME RISK.}

As well as considering each simulation individually, we can also examine changes that occur between the five successive environmental conditions in each of our 100 model replications. In particular, we can examine whether changes in betweenness caused by the closure of network connections are associated with changes in the levels of victimization: do streets which become more central experience more crime, and vice versa? Examining these changes - 'delta' values for both betweenness and victimization - is of interest for two reasons.

First, exploring the results in this way helps to control for the influence of initial conditions on each replication. In each simulation, just as in the real world, crime risk is dependent upon a number of factors the locations of offender agents' homes and activity nodes - which, in our simulation, are randomly generated for each replication. These factors cannot be captured by betweenness (or any other structural variable) and therefore represent a source of uncertainty in each simulation (a low-betweenness street, for example, may experience high crime simply because an offender happens to live nearby). Since these factors remain constant across environmental manipulations, however, this variation is accounted for when examining delta values.

Second, analysis of this type also offers insight into one of the potential policy implications of our findings. In light of the apparent relationship between centrality and crime, it may be suggested that network 
modification (e.g. road closure) could be a feasible means of either reducing crime or reshaping its distribution. By examining the changes under exactly this kind of intervention, we can explore the likely consequences of this.
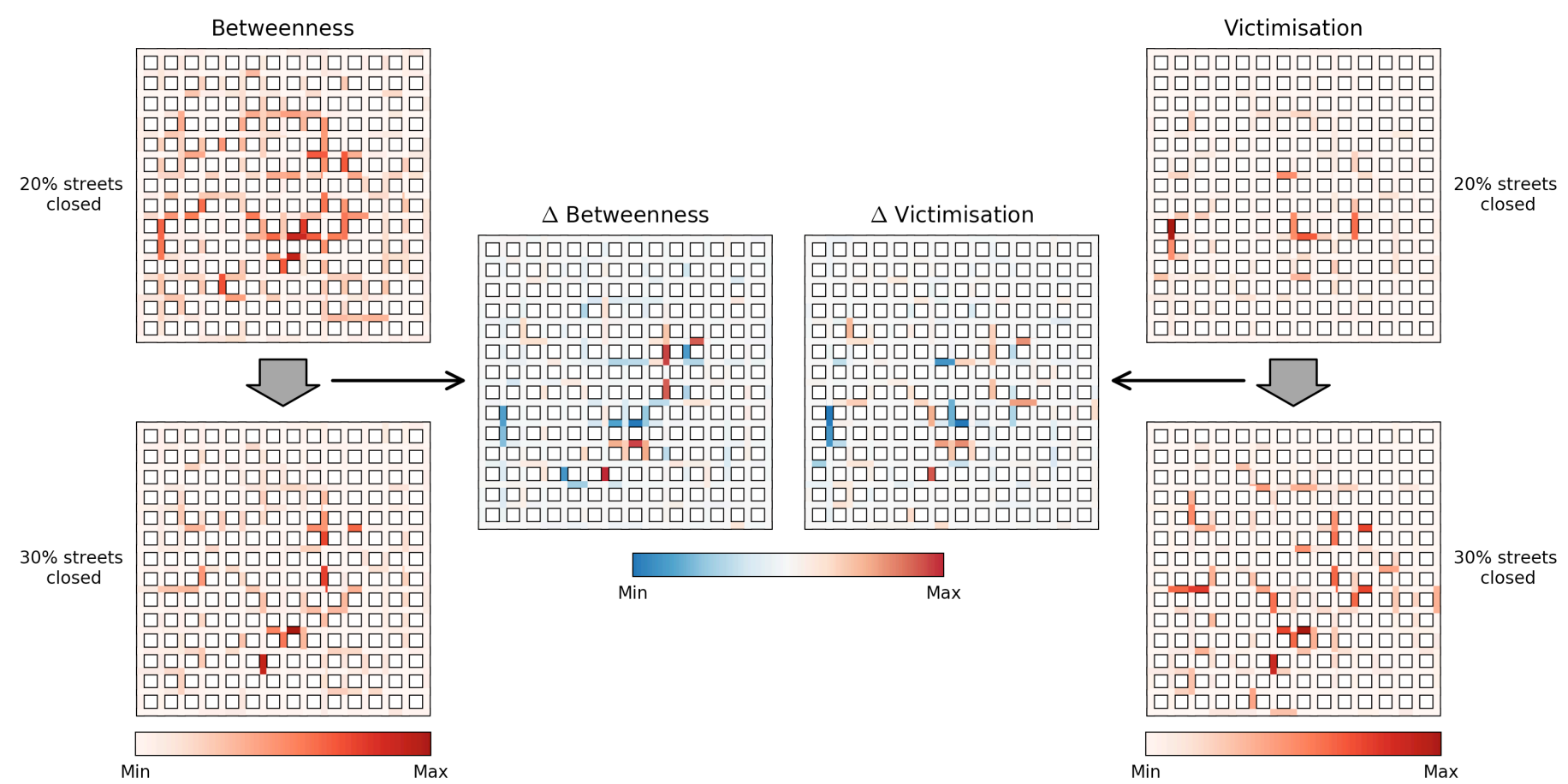

Figure 7. Illustrative comparison of changes in street segment betweenness and victimization. Maps on the left show changes in betweenness across experimental conditions, while maps on the right show the difference in victimization. Comparison of the two central maps reveals whether changes in betweenness are reflected in crime risk.

Figure 7 illustrates our analytical approach for one example replication. The maps on the left show the betweenness values of all residential street segments under the $20 \%$ and $30 \%$ closure conditions, with the impact of additional closures clear to see. The ' $\Delta$ Betweenness' panel summarizes these changes, showing the increases and decreases in each segment's betweenness under this manipulation. The maps on the right, on the other hand, show the proportion of victimization accounted for by each segment, with the ' $\Delta$ Victimization' plot again depicting the change between the two conditions. Comparison of the two ' $\Delta$ ' panels indicates broad qualitative agreement, suggesting a positive relationship between changes in betweenness and changes in crime risk. 
Exploring this relationship formally, regression coefficients for these difference values are presented in

Table 5. These demonstrate that the changes in centrality which result from environmental manipulations are positively associated with changes in crime risk. In simple terms, this means that streets which receive greater traffic as a result of changes in network structure will, as a result, experience higher rates of victimization (and vice versa). Importantly, this is true when all other environmental conditions are held constant.

Table 5. Spatial Regression Coefficients - Change in Street Segment Betweenness vs. Change in Crime Event Count*.

\begin{tabular}{|c|c|c|}
\hline \multirow{4}{*}{ 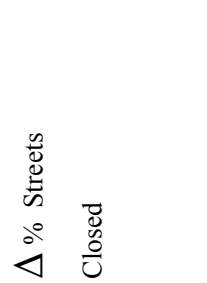 } & Guardianship & Guardianship \\
\hline & Configuration A: & Configuration B: \\
\hline & Control - No & Defensible Space \\
\hline & Guardians & \\
\hline $0 \%-10 \%$ & $3.69(1.43)$ & $2.91(1.50)$ \\
\hline $10 \%-20 \%$ & $4.60(1.76)$ & $3.63(1.43)$ \\
\hline $20 \%-30 \%$ & $5.73(1.58)$ & $4.73(1.29)$ \\
\hline $30 \%-40 \%$ & $7.35(1.57)$ & $6.00(1.36)$ \\
\hline
\end{tabular}

\footnotetext{
* For each replication $(\mathrm{n}=100)$, regression is performed on the 210 residential street segments in each environment; the mean of these values is given in this table, and the figures in brackets give the standard deviations.
}

The fact that the relationships observed become stronger as the network becomes more irregular reveals that the effect of network manipulation is non-linear. Initial disturbances to the regular structure have relatively little impact, since they affect activity spaces only minimally. As more connections are removed, however, it is increasingly likely that offenders will be forced to modify their routes. In such circumstances, they will naturally be drawn towards those segments which act as key conduits; that is, precisely those whose betweenness will have increased. Of course, this argument also applies to potential guardians, and the results therefore provide further evidence that their increased presence on these streets is not sufficient to counteract the increased exposure to offenders. Nevertheless, they do have a moderating effect: aggregate results imply that the increased offending on these streets is lower than it would be if the reductions on less-between streets had simply been displaced. 


\section{MODEL ROBUSTNESS}

As previously discussed, in addition to the two guardianship configurations examined above, we also carried out robustness tests to explore model outcomes across two further configurations to ensure that our observed results are not wholly driven by assumptions about both the relative strength and context dependency of guardianship capability. Replicating the global network analyses undertaken in Study 1, Table 6 depicts the results of these analyses. In summary, the outcomes that result from our two further active guardianship configurations are almost indistinguishable from those observed under configuration B.

Table 6. Robustness Test Results - Mean and Standard Deviation of Crime and Guardianship Event Counts by Network Permeability and Guardianship Configuration (100 model replications)

\begin{tabular}{|c|c|c|c|c|c|c|c|c|c|c|c|c|c|c|c|}
\hline & \multicolumn{6}{|c|}{ Crime Events } & \multicolumn{9}{|c|}{ Guardianship Events } \\
\hline $\begin{array}{l}00 \\
0 \\
0 \\
0 \\
0 \\
0 \\
0 \\
0 \\
0 \\
0 \\
0 \\
0\end{array}$ & 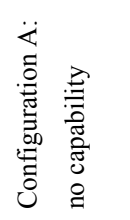 & 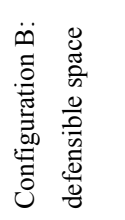 & 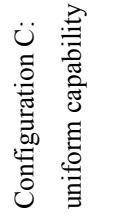 & 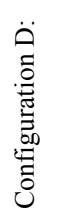 & $\begin{array}{l}0 \\
0 \\
0 \\
0 \\
0 \\
0 \\
0 \\
0 \\
0 \\
\frac{0}{0} \\
\frac{0}{0}\end{array}$ & 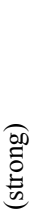 & 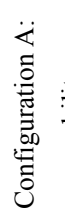 & 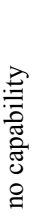 & 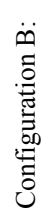 & 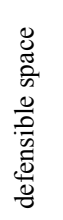 & 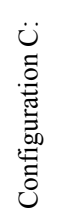 & 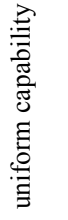 & 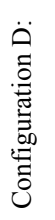 & $\begin{array}{l}0 \\
0 \\
0 \\
0 \\
0 \\
0 \\
00 \\
00 \\
\frac{1}{0} \\
\frac{0}{0}\end{array}$ & 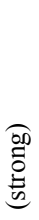 \\
\hline $0 \%$ & 719 (127) & $611(98)$ & $613(100)$ & 608 & (98) & & $0(0)$ & & 73 & (16) & 70( & 16) & 80( & (19) & \\
\hline $10 \%$ & $757(125)$ & $642(114)$ & $649(112)$ & 642 & (113) & & $0(0)$ & & 90 & (22) & 86 & 22) & 96( & (23) & \\
\hline $20 \%$ & $770(126)$ & $655(112)$ & $657(111)$ & 652 & $(107)$ & & $0(0)$ & & 107 & $(27)$ & 105 & $(25)$ & 115 & (29) & \\
\hline $30 \%$ & $714(113)$ & $583(106)$ & $582(105)$ & 574 & $(104)$ & & $0(0)$ & & 129 & $(30)$ & 124 & (29) & 131 & (28) & \\
\hline $40 \%$ & $544(103)$ & 394 (94) & 398 (99) & 393 & (90) & & $0(0)$ & & 145 & $(37)$ & 146 & (37) & 148 & (37) & \\
\hline
\end{tabular}

In addition, we also conducted a series of robustness tests exploring the impact of varying quantities of offenders inhabiting the world, and thus the relative mixing ratios of offenders and potential guardians. Again, replicating analyses undertaken in Study 1, Table 7 depicts the output of these analyses. As above, the functional form of our primary finding relating permeability and crime risk remains consistent in both additional model configurations where the world contains more $(\sim 10 \%$ of the population $)$ or less $(\sim 2.5 \%)$ offenders and simply scales resulting in greater or lesser amounts of crime respectively ${ }^{13}$.

\footnotetext{
${ }^{13}$ Readers are also directed to Birks, Townsley and Stewart (2012) where the underlying model is shown to be robust to a range of other significant parameter manipulations (e.g. number of routine activity nodes, offender motivation, etc.).
} 
Table 7. Robustness Test Results B - Mean and Standard Deviation of Crime and Guardianship Event Counts by Network Permeability, Guardianship Configuration and Ratio of Citizen to Offender Agents (100 model replications).

\begin{tabular}{|c|c|c|c|c|c|c|c|c|}
\hline & Crime Ev & & & & Guardia & p Events & & \\
\hline 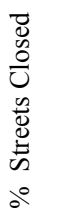 & 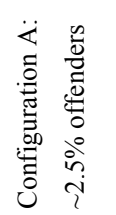 & 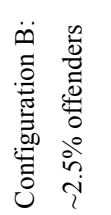 & 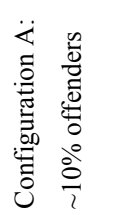 & 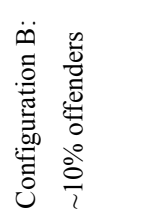 & 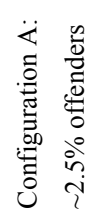 & 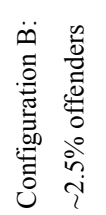 & 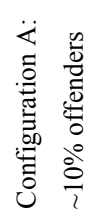 & 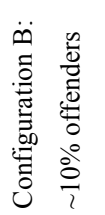 \\
\hline $0 \%$ & $349(94)$ & $291(72)$ & $1412(190)$ & $1226(140)$ & $0(0)$ & $36(12)$ & $0(0)$ & $141(20)$ \\
\hline $10 \%$ & $375(87)$ & $310(74)$ & $1501(202)$ & $1293(147)$ & $0(0)$ & $44(13)$ & $0(0)$ & $170(28)$ \\
\hline $20 \%$ & $378(87)$ & $310(71)$ & $1524(200)$ & $1287(148)$ & $0(0)$ & $56(19)$ & $0(0)$ & $201(34)$ \\
\hline $30 \%$ & $355(78)$ & $272(66)$ & $1422(220)$ & $1147(156)$ & $0(0)$ & $64(18)$ & $0(0)$ & $246(44)$ \\
\hline $40 \%$ & $264(72)$ & 185 (49) & $1075(225)$ & $784(150)$ & $0(0)$ & $71(21)$ & $0(0)$ & $281(66)$ \\
\hline
\end{tabular}

\section{DISCUSSION}

Quantifying the role that street networks play in situating, enabling and inhibiting crime events is a foundational, yet currently underdeveloped, research enterprise that has the potential to be transformational in a number of distinct settings. For theorists, such an understanding would support the empirical testing of theoretical constructs; for policy-makers it would inform prioritization of areas in terms of risk; and for practitioners it would provide applied principles for local policing and planning activities. While research increasingly demonstrates the significance of street segments in analyzing and understanding urban crime problems, studies aimed at revealing the relationship between street network structure, human activity patterns and crime risk are rare (for a review, see Johnson and Bowers 2010). This shortfall in knowledge is the direct consequence of several largely unassailable logistical constraints that encumber empirical studies in this area.

In this paper we aimed to circumvent some of these problems by combining parallel advances in mathematical and computational modeling of street networks and crime events. Doing so, we constructed a theoretically-informed computational agent-based model capable of investigating the likely impacts of street 
network permeability on offender and guardian activities patterns, and the resultant crime commission and guardianship events they give rise to. In particular we sought to assess the viability and veracity of two long standing hypotheses linking street network permeability, on-street guardianship, and crime risk - the encounter and enclosure hypotheses - that, for the reasons mentioned above, have remained largely inaccessible to traditional empirical enquiry.

In investigating these hypotheses we began by assessing the validity of our model, demonstrating that agents operating according to key principles of the routine activity approach, crime pattern theory and the rational choice perspective generated patterns of property victimization that were congruent with a range of wellestablished empirical regularities. Subsequently, we presented a suite of simulation experiments that systematically manipulated the environmental model within which our agents interacted, and, in turn, examined the crime events that resulted across a range of prescribed street network morphologies.

At the micro level, our results reveal that the betweenness centrality of street segments is significantly positively associated with property crime commission and prevention (through on-street guardianship). The former of these accords with the findings of Davies and Johnson (2015), suggesting that the behaviors encoded in our model provide a plausible explanation for the higher risk on more central streets. On the other hand, the relationship between guardianship and network structure is not one that has previously been examined empirically; indeed, the difficulty in establishing a counterfactual was a key motivator for the presented study. The relationship we observe is broadly in line with expectation: the higher rate of prevention on more central streets is simply a result of the higher throughput of potential guardians on such segments.

Taken together, our micro-level results allow us to draw stronger conclusions (in the context of our study) than were possible for Davies and Johnson. On one hand, the nature of our environment means that the possibility of confounding variables can be eliminated; our analysis of differences at successive levels of network modification is particularly conclusive on this point. Perhaps more significantly, though, the fact 
that guardianship could be observed explicitly in this study (albeit in a synthetic context) means that its potential influence on crime patterning can be better understood. Our results show that the increase in risk on more central street segments occurs despite a simultaneous increase in guardianship: here, the increased exposure simply outweighs the greater likelihood of prevention. This is a significant finding because it provides an indication of the relative magnitudes of the two effects.

Furthermore, results of our robustness tests that explore differing conceptualizations of the guardianship mechanism indicate that increasing or decreasing guardianship capability, both in context and non-context dependent situations, has limited impact on the frequency of guardianship events above and beyond levels associated with simply the presence of guardians. These results mimic observational studies of guardianship behavior and property crime risk (Reynald, 2009), in turn increasing the confidence we have in our model's validity.

At the macro level, our analysis was motivated by a desire to examine the contrasting 'encounter' and 'enclosure' hypotheses. Ultimately, our results provide support for both arguments. The fact that moderate deviations from regular network structure lead to increased offending supports the encounter hypothesis, such that offenders find greater opportunity for crime when their movements are concentrated. The reversal of this relationship at higher levels of manipulation, however, is consistent with the enclosure hypothesis, and can be explained by offenders' reduced awareness of viable targets. When guardianship is added, the combination of these two effects ultimately leads to a reduction in offending when the permeability of the network is reduced past a certain turning point. In fact, our micro-level analyses reveal that the decrease in victimization in these cases can largely be attributed to a localized encounter-like mechanism, such that increases in offender-target-guardian interactions on some routes drive subsequent reductions in offending. This finding is significant and highlights that the encounter and enclosure hypotheses may have different (and complementary) consequences at different spatial scales. 
Ultimately, the absence of a simple relationship between permeability and offending may itself be the most significant outcome of our analyses. This result reflects the complexity of the system of interest, and highlights that elements of both arguments are likely to be valid, depending on context. Our results suggest that both permeable and impermeable networks can reduce offending, but that structures between these extremes may be more risky. Furthermore, they demonstrate that macro-level reductions in offending may come at a cost for some areas, in the form of more pronounced concentrations of offending on certain wellused routes.

As we have previously discussed, the triangulation of theoretical, empirical and computational efforts should serve to advance our understanding of crime problems and the veracity of those theories we employ to describe them. Consequently, while we hope that our findings will support the incremental development of theory, they may also warrant consideration by those concerned with applied crime prevention. To this end, our models suggest that manipulation of street network structure can influence both the volume and distribution of crime, and it is therefore natural to consider how such manipulation might be realized in the real world. The most immediate way in which this could be done mirrors the approach used in our algorithm: the closure or disconnection of street segments. This is a strategy which has indeed been proposed as a potential crime control measure (Clarke 2004), and used in several real-world interventions (Lasley 1998; Matthews 1993, 1997). Though such studies have generally shown positive results, notions of connectivity and permeability were not their primary focus, and work remains to be done in examining whether any changes can be explained in these terms.

The complex nature of our results, however, suggests that the potential consequences of road closure are not straightforward. Our simulations indicate that closures may produce both positive and negative impacts on the incidence of victimization, contingent upon the existing road structure of the intervention area in question. This clearly highlights the importance of understanding the structure of an existing street network in order to predict the consequences of modifying it. However, it is also important to note that real-world 
closures can be targeted in a way that was not considered in our study: rather than removing connections at random, closures can be performed in such a way that a prescribed distribution of centrality is achieved.

Of course, the systematic closure of streets is unlikely to be practically viable in many real-world contexts, and it is therefore also worthwhile to consider alternative ways in which street networks can be shaped. The most natural avenue for this is through urban planning and design; that is, by altering network structures before, rather than after, they are constructed. In suggesting network manipulation as a course of action, however, we must be careful to note that the consequences of changes can be highly complex. Betweenness, for example, is largely a 'zero-sum' quantity: since the overall number of journeys to be taken remains constant, any changes which result in decreased use of a particular segment must be balanced by increases elsewhere. Interventions which seek to reduce crime on a street by reducing its betweenness may risk promoting offending elsewhere (in a way that is not necessarily predictable). This may not necessarily be an adverse outcome - the potential virtue of crime 'placement' has been discussed elsewhere (Barr and Pease 1990), and our results suggest that this may augment guardianship - but the issue reveals an underlying complexity that must be considered when considering such interventions.

Having summarized our findings and their immediate implications, we now outline several weaknesses associated with our approach and consider how they might be addressed in future work. Most immediately, we must acknowledge that our model remains just that: a model. While we have sought to validate it using commonly accepted techniques - and assessed its sensitivity to a number of significant parameter changes we can never be sure that it truly reflects the behaviors and interactions involved in real-world offending. This is, of course, true of any model (computational or otherwise), and our results should be viewed in the context of the general goal of the approach: to explore the consequences of hypothesized behaviors in a rigorous and quantifiable way. While our results are robust, therefore, they are only applicable to reality to the extent that the hypothesized behaviors are valid. It should also be noted that, like all studies that rely on recorded crime data, our efforts to validate our underlying model rest on the assumption that the signatures 
of crime against which we benchmark our simulated crime - which are predominantly derived from studies of reported crime - are representative of patterns of unreported crime.

Furthermore, our model clearly incorporates a number of assumptions which represent simplifications of reality. While the street network undoubtedly plays a significant role in influencing activity patterns, so do the relative locations and functions of facilities within that network. Given our aim to study the influence of network structure on crime, here we make the assumption that residential streets, agent residences, and agent activity nodes are randomly distributed throughout the environment. In reality, urban areas are likely to be more structured than this: residential properties typically cluster in certain parts of the street network, and offender residences often cluster within those residential areas.

Perhaps most importantly, our assumptions regarding citizen guardianship capability are, at best, empirically informed estimations. While, we have done our best to assess the impact of these necessary assumptions through varying model configurations and robustness tests (see Table 6), clearly empirical parameterization of these values is desirable. In the future, we hope to conduct empirical studies capable of estimating these values; however, designing and carrying out such experiments to produce reliable estimates is unlikely to be an easy task.

Nevertheless, while these weaknesses are acknowledged, we believe that the controlled nature of the model configurations means that their impact is limited within the confines of our stated goals. In each of the 100 model replications we perform, the only factor that is manipulated across conditions is the structure of the street network: all other factors are held constant and cannot be responsible for variation. In this sense, our approach is equivalent to examining the consequences of the modeled behaviors in 100 unique urban configurations. We suggest that this serves to attenuate the influence of the individual biases outlined above.

A final point concerns the fact that, in its current form, the model depicts routine activities as largely atemporal, such that agents only follow a spatially referenced routine. This fails to account for daily 
rhythms, for example, and the fluctuations of activity that may result from them. Here we believe that the impact of this assumption is likely to be diminished by the fact that our analysis is primarily concerned with property victimization. Since this is a crime against static targets, the confluence of offenders and targets is not dependent on the movements of target agents (which would be more strongly subject to temporal fluctuations), and its spatial character is therefore driven more strongly by offender awareness.

With regard to this point, an obvious extension to the work presented here is to utilize a similar model to simulate patterns of interpersonal victimization across varying street network configurations. We anticipate that even stronger effects than those observed here may arise in that case: the dynamic nature of victims is likely to drive criminal events even more strongly towards centers of activity.

A further opportunity to extend the external validity of the model relates to the consideration of alternative street network structures. The networks used in our experiments are variations on a basic grid structure and, while this is certainly an elementary configuration, it is far from true that all real-world networks conform to this template. Indeed, the structural properties of street networks are the subject of highly quantitative research outside of criminology, and attempts have been made to both develop typologies of network forms (Strano et al 2012; Louf and Barthelemy 2014) and model their evolution (e.g. Barthelemy and Flammini 2008). Future applications of our model could draw on such approaches by generating synthetic environments which represent generic examples of common network archetypes. Simulating crime events on this corpus of street networks would allow us seek generalizability across a wide range of environmental contexts.

In continuing these efforts, we hope to support a groundswell of research that demonstrates the importance of understanding crime risk at the street segment level - providing a more nuanced depiction of this critical unit of analysis, not as a solitary feature, but instead as part of a complex interconnected and interdependent entity. 


\section{REFERENCES}

Anselin, Luc. 1988. Spatial Econometrics: Methods and Models. Kluwer Academic Publishers, Dordrecht.

Barr, Robert, and Ken Pease. 1990. "Crime placement, displacement, and deflection." Crime and justice: 277-318.

Barthélemy, Marc, and Alessandro Flammini. 2008. "Modeling urban street patterns." Physical review letters 100, no. 13: 138702.

Beavon, Daniel J.K., Patricia L. Brantingham, and Paul J. Brantingham. 1994. The influence of street networks on the patterning of property offenses. Crime prevention studies 2: 115-148.

Berk, Richard. 2008. "How you can tell if the simulations in computational criminology are any good." Journal of Experimental Criminology 4, no. 3: 289-308.

Bevis, Carol and Julia B. Nutter J. 1977. Changing street layouts to reduce residential burglary. Minnesota Crime Prevention Center, Minnesota. https://www.ncjrs.gov/pdffiles1/Digitization/51937NCJRS.pdf Birks, Daniel. 2017. "Formal models of the crime event: Agent-based modelling in support of crime prevention." In Crime Prevention in the 21st Century, pp. 215-233. Springer International Publishing, Birks, Daniel, and Henk Elffers. 2014. "Agent-Based Assessments of Criminological Theory." In Encyclopedia of Criminology and Criminal Justice, pp. 19-32. Springer New York.

Birks, Daniel, Michael Townsley, and Anna Stewart. 2012. "Generative explanations of crime: using simulation to test criminological theory." Criminology 50, no. 1: 221-254.

Birks, Daniel, Michael Townsley, and Anna Stewart. 2014. "Emergent Regularities of Interpersonal Victimization An Agent-Based Investigation." Journal of Research in Crime and Delinquency 51, no. 1: 119-140.

Bonabeau, Eric. 2002. "Agent-based modeling: Methods and techniques for simulating human systems." Proceedings of the National Academy of Sciences 99, no. suppl 3: 7280-7287.

Bosse, Tibor, Henk Elffers, and Charlotte Gerritsen. 2010. "Simulating the dynamical interaction of offenders, targets and guardians." Crime Patterns and Analysis 3, no. 1: 51-66. 
Brantingham, Paul J., and Patricia L. Brantingham. 1993a. "Environment, routine and situation: Toward a pattern theory of crime." Advances in criminological theory 5: 259-294.

Brantingham, Patricia L., and Paul J. Brantingham. 1993b. "Nodes, paths and edges: Considerations on the complexity of crime and the physical environment." Journal of Environmental Psychology 13: 3-28.

Brantingham, Paul J., and Patricia L. Brantingham. 1981. Notes on the geometry of crime. In Environmental Criminology, eds. Paul J. Brantingham and Patricia L. Brantingham. Beverly Hills, CA: Sage.

Brantingham, Paul. J., Brantingham, Patricia. L., and Andresen, Martin. A. 2017. The Geometry of Crime and the Rules of Crime Pattern Theory. In Wortley, R. and Townsley, M., editors, Environmental Criminology and Crime Analysis. Routledge, Abingdon, Oxon, 2nd edition.

Brown, Barbara B., and Irwin Altman. 1981 "Territoriality and residential crime." In Environmental Criminology, eds. Paul J. Brantingham and Patricia L. Brantingham. Beverly Hills, CA: Sage.

Browning, Christopher R., and Aubrey L. Jackson. 2013 "The social ecology of public space: Active streets and violent crime in urban neighborhoods.". Criminology 51, no. 4: 1009-1043.

Chastain, Bryan, Fang Qiu, and Alex R. Piquero. 2016. Crime Theory Evaluation Using Simulation Models of Residential Burglary." American Journal of Criminal Justice: 1-20.

Clarke, Ronald V.G. 2004. Closing streets and alleys to reduce crime: should you go down this road?. US Department of Justice, Office of Community Oriented Policing Services

Cohen, Lawrence E., and Marcus Felson. 1979. Social change and crime rate trends: A routine activity approach. American Sociological Review 44:588-608.

Cornish, Derek B., and Ronald V. Clarke. 1986. The Reasoning Criminal: Rational Choice Perspectives on Offending. New York: Springer-Verlag.

Davies, Toby, and Shane D. Johnson. 2015. "Examining the relationship between road structure and burglary risk via quantitative network analysis." Journal of Quantitative Criminology 31, no. 3: 481-507.

Dijkstra, Edsger W. 1959. "A note on two problems in connexion with graphs." Numerische mathematik 1, no. 1: 269-271. 
Epstein, Joshua M. 1999. "Agent-based computational models and generative social science." Complexity 4, no. 5: 41-60.

Epstein, Joshua M., and Robert Axtell. 1996. Growing artificial societies: social science from the bottom up. Brookings Institution Press.

Felson, Marcus and Mary Eckert. 2015. Crime and everyday life. Thousand Oaks, CA:

Frith, Michael. J., Johnson, Shane. D., and Fry, Hannah. M. 2017, Role Of The Street Network In Burglars' Spatial Decision-Making. Criminology. DOI:10.1111/1745-9125.12133.

Garofalo, James, and David Clark. 1992. "Guardianship and residential burglary." Justice Quarterly 9, no. 3: 443-463.

Golledge, Reginald G., and Aron N. Spector. 1978. Comprehending the urban environment: Theory and practice. Geographical Analysis 9:403-26.

Groff, Elizabeth R. 2008. Adding the temporal and spatial aspects of routine activities: A further test of routine activity theory. Security Journal 21:95-116.

Groff, Elizabeth R. 2007 "Simulation for theory testing and experimentation: An example using routine activity theory and street robbery." Journal of Quantitative Criminology 23, no. 2: 75-103.

Groff, Elizabeth R., and Daniel Birks. 2008. "Simulating crime prevention strategies: A look at the possibilities." Policing 2, no. 2: 175-184.

Hillier, Bill. 1996. Space is the machine. Cambridge University Press, Cambridge

Hillier, Bill. 2004. "Can streets be made safe?." Urban design international 9, no. 1: 31-45.

Hindelang, Michael J., Michael R. Gottfredson, and James Garofalo. 1978. Victims of personal crime: An empirical foundation for a theory of personal victimization. Cambridge, MA: Ballinger

Hollis-Peel, Meghan E., Danielle M. Reynald, Maud van Bavel, Henk Elffers, and Brandon C. Welsh. "Guardianship for crime prevention: A critical review of the literature." Crime, law and social change 56, no. 1 (2011): 53-70.

Jacobs, Jayne. 1961 The death and life of Great American cities. Random House, New York 
Johnson, Shane D., and Kate J. Bowers. 2010. "Permeability and burglary risk: are cul-de-sacs safer?." Journal of Quantitative Criminology 26, no. 1: 89-111.

Lasley, James R. 1998. " Designing Out" Gang Homicides and Street Assaults. US Department of Justice, Office of Justice Programs, National Institute of Justice.

Lee, Ju-Sung, Tatiana Filatova, Arika Ligmann-Zielinska, Behrooz Hassani-Mahmooei, Forrest Stonedahl, Iris Lorscheid, Alexey Voinov, J. Gary Polhill, Zhanli Sun, and Dawn C. Parker. "The complexities of agent-based modeling output analysis." Journal of Artificial Societies and Social Simulation 18, no. 4 (2015): 4.

Louf, Rémi, and Marc Barthelemy. 2014. "A typology of street patterns." Journal of The Royal Society Interface 11, no. 101: 20140924.

Matthews, Roger. 1993. Kerb-crawling, prostitution and multi-agency policing. Crime prevention unit series paper no 43. Home Office, London.

http://www.popcenter.org/problems/street_prostitution/PDFs/fcpu43.pdf

Matthews, Roger. 1997. Developing more effective strategies for curbing prostitution. In: Clarke RV (ed)

Situational crime prevention: successful case studies, 2nd edn. Criminal Justice Press, Monsey

Moriarty, Thomas. 1975 "Crime, commitment, and the responsive bystander: Two field experiments." Journal of Personality and Social Psychology 31, no. 2: 370.

Newman, Oscar. 1972. Defensible space. New York: Macmillan,

O'Sullivan, David. 2004 Too Much of the Wrong Kind of Data: Implications for the Practice of Micro-Scale Modeling. In M. F. Goodchild \& D. G. Janelle (Eds.), Spatially Integrated Social Science (pp. 95- 107). New York: Oxford University Press.

Reynald, Danielle M. 2011. Guarding against crime: Measuring guardianship within routine activity theory. Ashgate Publishing, Ltd.

Reynald, Danielle M. 2009. "Guardianship in action: Developing a new tool for measurement." Crime Prevention \& Community Safety 11, no. 1: 1-20. 
Reynald, Danielle M., and Henk Elffers. 2009, "The Future of Newman's Defensible Space Theory Linking Defensible Space and the Routine Activities of Place." European Journal of Criminology 6, no. 1: 25-46.

Strano, Emanuele, Matheus Viana, Luciano da Fontoura Costa, Alessio Cardillo, Sergio Porta, and Vito Latora. 2013. "Urban street networks, a comparative analysis of ten European cities." Environment and Planning B: Planning and Design 40, no. 6: 1071-1086.

Townsley, Michael, and Daniel Birks. 2008. "Building better crime simulations: systematic replication and the introduction of incremental complexity." Journal of Experimental Criminology 4, no. 3 (2008): 309-333.

Weisburd, David. 2015. "The law of crime concentration and the criminology of place." Criminology 53, no. 2: $133-157$.

Weisburd, David, Anthony A. Braga, Elizabeth R. Groff, And Alese Wooditch. 2017. "Can Hot Spots Policing Reduce Crime In Urban Areas? An Agent - Based Simulation." Criminology 55, No. 1: 137-173.

Wilensky, Uri. 1999. NetLogo, http://ccl.northwestern.edu/netlogo/, Center for Connected Learning and Compute Based Modeling, Northwestern University, Evanston, IL.

White, Garland F. "Neighborhood permeability and burglary rates." Justice Quarterly 7, no. 1 (1990): 5767. 


\section{Appendix A. Key Model Parameters}

\begin{tabular}{|c|c|c|c|c|c|}
\hline Parameter & Description / Notes & Value & $\begin{array}{l}\text { Initialization } \\
\text { Conditions } \\
\end{array}$ & Rationale & Manipulated? \\
\hline World size & $\begin{array}{l}\text { Specifies the size of the street grid } \\
\text { upon which all interactions take } \\
\text { place. Specified in the number of } \\
\text { intersections that make up the grid } \\
\text { in } \mathrm{x} \text { and y directions. }\end{array}$ & $15 \times 15$ & NA & $\begin{array}{l}\text { Size sufficiently large to } \\
\text { generate agent populations } \\
\text { that are not overly sensitive } \\
\text { to initial conditions and not } \\
\text { so large as to require } \\
\text { unavailable computational } \\
\text { resources. }\end{array}$ & $\begin{array}{l}\text { Preliminary unit } \\
\text { tests }{ }^{\mathrm{A}} \text { of other } \\
\text { environments - } \\
5 \times 5,10 \times 10 \\
20 \times 20,50 \times 50)\end{array}$ \\
\hline Land parcel density & $\begin{array}{l}\text { The number of property nodes per } \\
\text { street segment. }\end{array}$ & 10 & NA & As above. & $\begin{array}{l}\text { Preliminary unit } \\
\text { tests }^{\mathrm{A}} \text { of lesser and } \\
\text { greater density. }\end{array}$ \\
\hline $\begin{array}{l}\text { Percentage of streets } \\
\text { residential }\end{array}$ & $\begin{array}{l}\text { Percentage of street segments zoned } \\
\text { residential and allocated residential } \\
\text { target agents. }\end{array}$ & $50 \%$ & $\begin{array}{l}\text { At simulation } \\
\text { initialization a } \\
\text { randomly selected } 50 \% \\
\text { of streets are classified } \\
\text { residential. }\end{array}$ & $\begin{array}{l}\text { Not all streets are } \\
\text { residential. }\end{array}$ & No. \\
\hline $\begin{array}{l}\text { Number of residential } \\
\text { targets }\end{array}$ & $\begin{array}{l}\text { The total number of residential } \\
\text { target agents, and thus opportunities } \\
\text { for residential burglary. }\end{array}$ & $\begin{array}{l}2100 \text { (derived from the } \\
\text { number of street segments } \\
\text { modeled, land parcel } \\
\text { density and the proportion } \\
\text { of streets residential). }\end{array}$ & NA & As above. & No. \\
\hline $\begin{array}{l}\text { Percentage population } \\
\text { offenders }\end{array}$ & $\begin{array}{l}\text { Each residential target has an agent } \\
\text { associated with it. There is a } 95 \% \\
\text { chance an agent will be a citizen } \\
\text { and a } 5 \% \text { chance they will be an } \\
\text { offender. }\end{array}$ & $\begin{array}{l}3 \text { configurations: } \\
\text { Primary configuration } \\
(\sim 5 \% \text { offenders }) \text { and } 2 \\
\text { robustness configurations } \\
(\sim 2.5 \%, \sim 10 \% \text { offenders })\end{array}$ & NA & $\begin{array}{l}\text { Empirical estimation of the } \\
\text { proportion of the population } \\
\text { offenders. }\end{array}$ & $\begin{array}{l}\text { Yes }-3 \\
\text { configurations: } 1 \\
\text { primary and } 2 \\
\text { robustness tests. } \\
\text { See Table } 6 .\end{array}$ \\
\hline $\begin{array}{l}\text { Proportion of } \\
\text { intersection to property } \\
\text { node street segments } \\
\text { closed }\end{array}$ & $\begin{array}{l}\text { The count of street links between } \\
\text { intersections and property nodes } \\
\text { closed - in effect converting } \\
\text { through-streets to cul-de-sacs. As } \\
\text { this value increases the global } \\
\text { permeability of the street network } \\
\text { decreases. }\end{array}$ & $\begin{array}{l}5 \text { configurations: } \\
0 \% \text { (Control Model); } \\
10 \% ; 20 \% ; 30 \% ; 40 \% \text {. }\end{array}$ & $\begin{array}{l}\text { Randomly selected at } \\
\text { simulation } \\
\text { initialization. } \\
\text { Algorithm ensures that } \\
\text { the street network does } \\
\text { not become } \\
\text { disconnected as a result } \\
\text { of road closure. All } \\
\text { closures sequential } \\
\text { between conditions. }\end{array}$ & $\begin{array}{l}\text { Arbitrary selection to (1) } \\
\text { allow estimates of impact on } \\
\text { crime commission of } \\
\text { increasingly less permeable } \\
\text { street network structures; }(2) \\
\text { minimize computational } \\
\text { burden. }\end{array}$ & $\begin{array}{l}\text { Yes }-5 \\
\text { configurations. }\end{array}$ \\
\hline $\begin{array}{l}\text { Citizen and offender } \\
\text { agent routine activity } \\
\text { space }\end{array}$ & $\begin{array}{l}\text { The number of property nodes } \\
\text { allocated to each offender and } \\
\text { citizen agent that make up their } \\
\text { routine activity space. }\end{array}$ & $\begin{array}{l}1 \text { home node, } 4 \text { other } \\
\text { property nodes }\end{array}$ & $\begin{array}{l}\text { Randomly allocated at } \\
\text { simulation } \\
\text { initialization. }\end{array}$ & $\begin{array}{l}\text { As in Birks et al (2012, } \\
\text { 2014). }\end{array}$ & $\begin{array}{l}\text { No. Relevant } \\
\text { robustness tests } \\
\text { conducted in Birks } \\
\text { et al. } 2012\end{array}$ \\
\hline $\begin{array}{l}\text { Residential target } \\
\text { utility. }\end{array}$ & $\begin{array}{l}\text { Represents the utility associated } \\
\text { with a given residential target. This } \\
\text { value is expressed in terms of the } \\
\text { probability that an offender agent } \\
\text { will find a particular target } \\
\text { attractive. }\end{array}$ & $\mathrm{U}(0 \mid 1)$. & $\begin{array}{l}\text { Heterogeneous across } \\
\text { residential property } \\
\text { agents. Randomly } \\
\text { allocated at simulation } \\
\text { initialization. }\end{array}$ & $\begin{array}{l}\text { Abstract formalism of } \\
\text { rational choice propositions } \\
\text { that some targets are more } \\
\text { attractive than others. }\end{array}$ & No. \\
\hline $\begin{array}{l}\text { Guardianship } \\
\text { capability of citizen } \\
\text { agents }\end{array}$ & $\begin{array}{l}\text { Represents the probability that a } \\
\text { citizen agent present at the } \\
\text { commission of a crime event will } \\
\text { prevent that crime from occurring. } \\
\text { Context dependent on commission } \\
\text { location relative to potential } \\
\text { guardians home such } \text { p(guard) })_{\text {home }} \\
\text { represents the probability crime } \\
\text { encountered in the guardian's home } \\
\text { street is prevented; p(guard) } \text { away } \\
\text { away from home. }\end{array}$ & $\begin{array}{l}4 \text { configurations explored: } \\
\text { Control: } p \text { (guard })=0 \\
\text { Defensible Space: } \\
p(\text { guard })_{\text {home }}=.33 \\
p(\text { guard })_{\text {away }}=.20 \\
\text { Uniform Capability: } \\
p(\text { guard })=.20, \\
\text { Defensible Space }- \\
(\text { strong }): \\
p(\text { guard })_{\text {home }}=.50 \\
p(\text { guard })_{\text {away }}=.20\end{array}$ & NA & $\begin{array}{l}\text { Control configuration } \\
\text { provides baseline. } \\
\text { Defensible space } \\
\text { configuration reflects theory } \\
\text { concerning context } \\
\text { dependency of capability. } \\
\text { Initial values informed by } \\
\text { willingness to intervene } \\
\text { experiments. } \\
2 \text { additional configurations } \\
\text { explore impact of varying } \\
\text { levels of capability. }\end{array}$ & $\begin{array}{l}\text { Yes }-4 \\
\text { configurations: } 2 \\
\text { primary and } 2 \\
\text { robustness tests } \\
\text { (see Table 5). }\end{array}$ \\
\hline $\begin{array}{l}\text { Offender agent } \\
\text { learning rate. }\end{array}$ & $\begin{array}{l}\text { Parameter defining the rate at which } \\
\text { offender agents gain awareness of } \\
\text { their current surroundings via the } \\
\text { spatial learning behavior. }\end{array}$ & .025 & $\begin{array}{l}\text { Uniform across all } \\
\text { offenders. }\end{array}$ & $\begin{array}{l}\text { As in Birks et al. 2012, } 2014 \\
\text { this value is calibrated to } \\
\text { equate to a location being } \\
\text { visited } 50 \text { times before the } \\
\text { probability an offender is } \\
\text { sufficiently aware of a } \\
\text { location to attempt } \\
\text { commission approaches } p(1)\end{array}$ & No. \\
\hline
\end{tabular}

A. Unit tests, for the sake of computational tractability, involve initial small-scale robustness tests whereby a parameter of interest is manipulated and the impact of that manipulation scrutinized to ensure that key model outcomes are not highly sensitive to manipulations. 
Appendix B. Model Validity - Mean and Standard Deviation of Nearest Neighbor Index (Crime Spatial Concentration), Gini Coefficient (Victimization), and Pearson's Coefficient of Skewness for Journey to Crime Curves by Network Structure and Guardianship Configuration

\begin{tabular}{|c|c|c|c|}
\hline$\%$ Streets Closed & $\begin{array}{l}\text { Nearest Neighbor } \\
\text { Index (Euclidian) } \\
\text { (Crime Spatial } \\
\text { Concentration) }\end{array}$ & $\begin{array}{l}\text { Gini Coefficient } \\
\text { (Victimization) }\end{array}$ & $\begin{array}{l}\text { Journey to Crime } \\
\text { Skewness } \\
\text { (Euclidian) }\end{array}$ \\
\hline \multicolumn{4}{|c|}{ Guardianship configuration A: control - no capability } \\
\hline $0 \%$ & $0.38(0.04)$ & $0.33(0.05)$ & $1.8(0.24)$ \\
\hline $10 \%$ & $0.35(0.04)$ & $0.33(0.05)$ & $1.8(0.22)$ \\
\hline $20 \%$ & $0.33(0.03)$ & $0.33(0.04)$ & $1.75(0.22)$ \\
\hline $30 \%$ & $0.31(0.04)$ & $0.32(0.04)$ & $1.55(0.22)$ \\
\hline $40 \%$ & $0.31(0.04)$ & $0.31(0.04)$ & $1.07(0.25)$ \\
\hline \multicolumn{4}{|c|}{ Guardianship configuration B: defensible space } \\
\hline $0 \%$ & $0.41(0.04)$ & $0.31(0.05)$ & $1.8(0.25)$ \\
\hline $10 \%$ & $0.38(0.04)$ & $0.31(0.05)$ & $1.81(0.23)$ \\
\hline $20 \%$ & $0.35(0.04)$ & $0.31(0.05)$ & $1.78(0.21)$ \\
\hline $30 \%$ & $0.35(0.04)$ & $0.3(0.05)$ & $1.67(0.23)$ \\
\hline $40 \%$ & $0.38(0.05)$ & $0.25(0.06)$ & $1.23(0.29)$ \\
\hline \multicolumn{4}{|c|}{ Guardianship configuration C: uniform capability } \\
\hline $0 \%$ & $0.41(0.04)$ & $0.31(0.05)$ & $1.8(0.23)$ \\
\hline $10 \%$ & $0.38(0.04)$ & $0.31(0.05)$ & $1.83(0.21)$ \\
\hline $20 \%$ & $0.35(0.04)$ & $0.31(0.04)$ & $1.78(0.23)$ \\
\hline $30 \%$ & $0.35(0.04)$ & $0.3(0.05)$ & $1.67(0.25)$ \\
\hline $40 \%$ & $0.38(0.05)$ & $0.25(0.06)$ & $1.23(0.27)$ \\
\hline \multicolumn{4}{|c|}{ Guardianship configuration D: strong home advantage } \\
\hline $0 \%$ & $0.41(0.04)$ & $0.31(0.05)$ & $1.78(0.24)$ \\
\hline $10 \%$ & $0.38(0.04)$ & $0.31(0.05)$ & $1.83(0.23)$ \\
\hline $20 \%$ & $0.36(0.04)$ & $0.31(0.04)$ & $1.81(0.2)$ \\
\hline $30 \%$ & $0.35(0.04)$ & $0.29(0.05)$ & $1.66(0.22)$ \\
\hline $40 \%$ & $0.38(0.05)$ & $0.25(0.05)$ & $1.23(0.3)$ \\
\hline
\end{tabular}

